\title{
Is semantic priming due to association strength or feature overlap? A microanalytic review
}

\author{
KEITH A. HUTCHISON \\ Washington University, St. Louis, Missouri
}

\begin{abstract}
In a recent meta-analysis, Lucas (2000) concluded that there is strong evidence of an overall pure semantic priming effect but no evidence of priming based purely on association. In the present review, I critically examine the individual studies claiming evidence of featural and associative relations in semantic memory. The most important conclusion is that automatic priming appears to be due to both association strength and feature overlap. Mediated associates provide the strongest evidence of automatic associative priming, whereas functional associates, synonyms, and antonyms instead support priming based on feature overlap. In contrast, automatic priming does not occur for category coordinates or perceptually similar items, at least when presented in the visual modality. The status of other relations, such as collocates, episodic relatives, and script relations, is unclear and requires further experimentation. Implications for current models of semantic representation and priming are discussed.
\end{abstract}

Semantic memory is often described as our organized general world knowledge and has been metaphorically compared to a dictionary, encyclopedia, or thesaurus (Katz \& Fodor, 1963; Lyons, 1968; McKoon \& Ratcliff, 1979; Smith, 1978). As a dictionary or lexicon, our semantic memory contains information concerning a concept's identity, spelling, and pronunciation. As an encyclopedia, semantic memory contains dense information regarding a concept's meaning. Finally, as a thesaurus, semantic memory contains information about which other words have similar meanings. Importantly, all three of these sources contain some information concerning a concept's meaning. Although an encyclopedia can provide the most detailed description of a concept, a thesaurus can also be used to uncover its meaning by listing other, highly similar concepts.

Representations of word forms and their corresponding concepts are generally conceived as residing within separate, but connected, lexical and semantic networks (Anderson, 1983; Collins \& Loftus, 1975; McClelland \& Rumelhart, 1985; McNamara, 1992; Seidenberg \& McClelland, 1989). For instance, in Collins and Loftus's (1975) model, words are organized in a lexical network according to spelling and sound such that each word is linked to other words similar in orthography and/or phonol-

This research was conducted in partial fulfillment of the requirements for the PhD degree at the University at Albany, State University of New York, December 2001. I thank the dissertation committee chair, Jim Neely, as well as the other members of the dissertation committee, Tram Neill and Jeanette Altarriba, for their many thoughtful suggestions. I also thank David Balota, Derek Besner, Margery Lucas, and Doug Nelson for their helpful comments and discussions. Correspondence concerning this article should be addressed to K. A. Hutchison, who is now at the Department of Psychology, 304 Traphagen Hall, Montana State University, Bozeman, MT 59717-3440(e-mail: khutch@ montana.edu). ogy. Fodor (1983) later proposed that the lexical network also contains links between words that tend to co-occur in language, such as mouse and cheese.

Whereas words are represented in a lexical network, the concepts to which they refer are often described as represented within a separate, semantic memory. Concepts within this semantic network could be represented as either holistic units (Anderson, 1983; Collins \& Loftus, 1975; McNamara, 1992) or distributed units (Kawamoto, 1993; Masson, 1995; Moss, Hare, Day, \& Tyler, 1994; Plaut, 1995). As an example of a holistic model, that of Collins and Loftus (1975) suggested that holistic representations (i.e., nodes) of concepts reside in a semantic network. They argued that these nodes share connections with other nodes of similar meaning. In general, holistic models assume that concepts are connected to each other through learned associations. For instance, the node CHERRY may become connected to the node RED because RED is a strongly associated property of the concept CHERRY. ${ }^{1}$ The more properties (i.e., features) two concepts (e.g., CHERRY and APPLE) have in common, the more connections exist between the two nodes via these properties. Moreover, connections exist between the semantic level and the lexical level, such that a lexical node (representing a particular word) would be directly connected to its corresponding concept in the semantic network.

In contrast with the holistic models, the argument behind distributed models of semantic memory is that the units of a network are not whole words but simple, highly interconnected features. The learning of the meaning of a word (e.g., cherry) in this type of model is defined as changes in the weights of the connections between the preexisting features. A certain pattern of weighted features (e.g., round, juicy, small, edible, grows on trees) comes to represent a particular concept. In this manner, the knowledge of a concept is distributed over many dif- 
ferent features and, in turn, each feature is contained in the knowledge of multiple concepts.

As might be imagined, testing between these models is extremely difficult. The main reason for this difficulty is that both theories propose that features or properties of a concept are a critical part of that concept's semantic structure. The difference between the models concerns the process by which one concept is said to influence the recognition of another concept. Many holistic models of semantic memory suggest that when a word is read or heard, activation automatically spreads from the semantic representation (node) of that word to the representations (nodes) of semantically associated neighbors (Anderson, 1983; Collins \& Loftus, 1975; Neely, 1977; Posner \& Snyder, 1975). Therefore, being exposed to the word $d o g$ will preactivate concepts such as CAT, BARK, and LEASH because they tend to be associated. In contrast, many distributed models do not make the assumption of an activation process that spreads across links in a semantic network. Instead, in these models thinking of a concept such as DOG will facilitate the processing of related concepts, such as CAT, because the features that make up the two concepts (e.g., fur, claws) largely overlap. Thus, whereas many holistic models emphasize a spreading activation process from DOG to similar concepts such as CAT, features of the concept such as FUR, or even those of other lexical items that co-occur, such as LEASH, most distributed models emphasize only the similarity in features between concepts.

The most common procedure for experimentally investigating the structure of semantic memory is the semantic priming paradigm. In this paradigm, researchers typically ask participants to either read aloud or make lexical (i.e., "word" or "nonword") decisions to target items. The semantic priming effect refers to the consistent observation that people respond faster to a target word (e.g., cat) when it is preceded by a semantically related prime (e.g., dog) rather than by an unrelated prime (e.g., table). Of importance, the semantic relation between the two concepts decreases response latency to the target word, even though neither pronunciation tasks nor lexical decision tasks (LDTs) require participants to access a word's meaning. ${ }^{2}$ Because semantic relatedness exerts an influence in such simple (nonsemantic) tasks, researchers have suggested that semantic priming reflects the underlying organization of concepts in semantic memory (Meyer \& Schvaneveldt, 1971; Meyer, Schvaneveldt, \& Ruddy, 1975).

Early researchers interpreted semantic priming in terms of associative links, suggesting that reading a prime word leads to automatic spreading activation to the representations of related concepts (Anderson, 1983; Collins \& Loftus, 1975; Neely, 1977; Posner \& Snyder, 1975). In line with Posner and Snyder, the term automatic here suggests that the process occurs quickly and unintentionally, even if one is simultaneously engaged in other activities. ${ }^{3}$ However, although such results are compatible with a spreading activation process, most demonstrations of semantic priming are equally compatible with a distributed representation if one makes the reasonable assumption that a target containing many of the same features as the prime does will be encoded faster than a target with little or no featural similarity to the prime (Fischler, 1977).

The quest to determine whether semantic priming is due primarily to association strength or to feature overlap has not been easy, since results from such studies are often difficult to interpret. The first reason for this difficulty is that participants in semantic priming studies often use complex task-specific strategies in order to perform the task more efficiently, making it difficult to determine the extent to which any resulting priming actually reflects the underlying semantic structure. This difficulty becomes exacerbated as the processing required by a particular task becomes more complex. Two particular conscious strategies that could potentially obscure the detection of any automatic activation in priming tasks have been suggested: expectancy generation and postlexical semantic matching (see Neely, 1991, for a review). The expectancy generation component involves the use of the context provided by the prime to anticipate consciously the approximate area in the network (or collection of features, if a distributed representation is assumed) containing the target word. Unlike more automatic processes, strategic shifts in attention supposedly take time to occur, require attentional capacity, and are under strategic control (Becker, 1980; Posner \& Snyder, 1975). Several researchers have uncovered evidence of the dissociation of automatic and expectancybased priming by manipulating either the proportion of related prime-target pairs in an experiment (the socalled relatedness proportion, or RP) or the time interval (the so-called stimulus onset asynchrony, or SOA) between the onset of the prime word (at which point people could start generating an expectancy) and the presentation of the probe word (de Groot, 1984; den Heyer, 1985; den Heyer, Briand, \& Dannenbring, 1983; Neely, 1977; Tweedy, Lapinski, \& Schvaneveldt, 1977). Unfortunately, there is no universal SOA that distinctly separates conscious from unconscious processing, and the SOA necessary to demonstrate automatic priming may vary from task to task (see Hutchison, Neely, \& Johnson, 2001).

According to Neely and Keefe (1989), an additional semantic matching strategy occurs in the LDT. This strategy presumably occurs under conditions in which a majority of the unrelated prime-target pairs contain nonword targets (i.e., a high nonword ratio, or NWR). In such cases, the presence of a prime-target relation indicates that the target is a word, whereas the absence of such a relation indicates that the target is most likely a nonword. Participants who become aware of this contingency may begin to use prime-target relatedness strategically to facilitate their lexical decisions by checking back after the presentation of a target to see if it is related to the prime and by using the presence or absence 
of such a relation to bias a "word" or "nonword" response, respectively. Because the NWR is typically confounded with the RP, either expectancy or semantic matching (or both) likely contributes to RP effects in the LDT. However, in the pronunciation task (or other tasks that do not require binary decisions), this semantic matching process should not contribute to performance, since knowledge of prime-target relatedness per se cannot aid in the execution of the correct response.

The second problem facing researchers is the difficulty in separating association strength from feature overlap. In a vast majority of semantic priming studies, items obtained from association norms have been used, in which people are given a cue such as $d o g$ and asked to respond with the first word that comes to mind. The association strength of a given pair (e.g., dog-cat) refers to the percentage of people responding with the target word (cat) when given the cue ( $d o g)$. Although a common assumption about association norms is that they reflect primarily the phrasal contiguity between items, many researchers have suggested that they actually contain a conglomeration of different types of relations (Deese, 1965; see Moss, Ostrin, Tyler, \& Marslen-Wilson, 1995, for a thorough discussion). The frequently used noun and adjective stimuli from the Kent-Rosanoff (1910) and Palermo-Jenkins (1964) norms can help demonstrate this point. On the basis of previous studies and an informal analysis, I classified each stimulus and its primary associate in these norms into 1 or more of 14 possible relations. The results of this analysis are presented in Table 1. Notice that the total percentage listed across subgroups is greater than $100 \%$. This is because several stimuli (e.g., cat-dog) fall into more than one classification (e.g., natural category and script relation). Inspection of Table 1 reveals that there are many ways in which two words can be associated. Moreover, it could be argued that each of these association types involves some type of overlap in semantic features. For instance, synonyms have an almost complete overlap in meaning,

Table 1

Percentage Rates of 14 Types of Association in the Palermo-Jenkins Norms for College-Aged Adults

Association Type (and Example) Percentage Rate

$\begin{array}{lr}\text { Synonyms (afraid-scared) } & 14.1 \\ \text { Antonyms (day-night) } & 24.3 \\ \text { Natural category (sheep-goat) } & 9.1 \\ \text { Artificial category (table-chair) } & 5.1 \\ \text { Perceptual only (pizza-saucer) } & 0.0 \\ \text { Supraordinate (dog-animal) } & 5.6 \\ \text { Perceptual property (canary-yellow) } & 11.1 \\ \text { Functional property (broom-sweep) } & 12.1 \\ \text { Script relation (orchard-apple) } & 6.1 \\ \text { Instrument (broom-floor) } & 6.1 \\ \text { Forward phrasal associate (baby-boy) } & 11.6 \\ \text { Backward phrasal associate (boy-baby) } & 4.1 \\ \text { Associated properties (deep-dark) } & 1.0 \\ \text { Unclassified (mouse-cheese) } & 5.1\end{array}$

Note-Because many stimulus pairs fall into more than one classification, the total percentage listed is greater than $100 \%$. and antonyms may represent a special case of category members that also often co-occur in a sentence and are opposites on a single critical featural dimension. Category members, property relations, and supraordinate relations also involve overlap in certain features. In fact, even phrasal associates, such as fruit-fly or spider-web, though often composed of separable individual concepts, combine to form a unitary semantic concept with its own unique pattern of features. Therefore, studies of priming based only on association strength are virtually useless for distinguishing between whether such effects are due to association or to feature overlap.

Similarly, although priming for items from category norms has been taken as evidence that semantic memory representations are organized primarily by feature overlap, the associations between items in these norms render such conclusions suspect. For instance, high-dominance exemplars do tend to share more features with the category label (e.g., bird-robin); however, they also tend to be more strongly associated with the category label (and are higher frequency words) than are low-dominance exemplars (e.g., bird-penguin). Thus, item dominance, defined in terms of production frequency in category norms, may reflect associative strength just as easily as feature overlap. In fact, the terms dominance and association strength have been used interchangeably (Lorch, 1982).

In other studies, researchers give participants primetarget pairs and ask them to rate each pair in terms of the semantic similarity of its components. However, there is no universal method for determining similarity in this task, and pairs' ratings can vary drastically depending on (1) the other words used in the norming process, (2) how the researcher defines similar for the participants, (3) the order in which the words are presented, (4) the participants' instructional or response set, and (5) the extent to which the two items are associated.

Close inspection of both associative and categorical norms therefore leads one to the uncomfortable conclusion that they are not nearly as pure as has been assumed. As with associative priming, categorical priming is completely ambiguous in providing evidence concerning the nature of semantic representation. The dominance structure of categorical norms or similarity ratings in other norms may merely reflect association strength between the stimuli. Therefore, studies concluding that their obtained priming is purely associative or featural should be interpreted with caution if they are based on the use of these norms.

\section{LUCAS'S (2000) SEMANTIC PRIMING META-ANALYSIS}

In a recent meta-analysis of studies testing for semantic priming in the absence of association, Lucas (2000) examined the overall effect size from 26 studies (accounting for 116 experiments) that claimed to somehow control for association strength, excluding studies in which 
special populations were used or complex semantic categorization tasks were involved. Such a meta-analytic technique allows a researcher to summarize a large number of studies quantitatively, combining effects across both published and unpublished studies, to derive a more stable estimate of an effect than one could obtain from a single experiment. As Rosenthal and DiMatteo (2001) recently argued, other benefits of meta-analysis include that they (1) provide a more objective and quantitative review of a phenomenon, (2) prevent overreliance on a particular significance test in an single experiment, and (3) allow the researcher to examine potential moderating variables (e.g., SOA, RP, task) in producing an effect.

On the basis of the results of her analysis, Lucas (2000) concluded that (1) there is evidence of an overall "pure semantic" priming effect in the absence of an association, (2) there is no evidence of priming based purely on association in the absence of semantic relation, (3) pure semantic priming is insensitive to the effects of SOA or $\mathrm{RP}$, (4) pure semantic priming effects are similar across different types of LDT but are smaller in pronunciation tasks, (5) an associative boost exists, such that items sharing a semantic association show larger priming effects than items lacking any semantic association, and (6) there may be a difference across different types of stimuli, with pure semantic priming being greatest for functionally related items and least for perceptually related items.

Lucas's (2000) first conclusion is of most importance and implies that semantic priming is driven primarily by feature overlap rather than by association. Her second and fifth conclusions further support this claim, suggesting that some semantic relation is necessary for associations to influence priming. Also, as did Chiarello, Burgess, Richards, and Pollock (1990) and McRae and Boisvert (1998), Lucas (2000) argued that the associative boost is actually due to associated pairs' sharing a greater overlap in semantic features. Her third conclusion (that semantic priming is insensitive to SOA and RP) suggests that the semantic priming effects obtained were primarily automatic. Finally, in describing her fourth conclusion-that pure semantic priming effects are smaller in pronunciation tasks-Lucas (2000) cited Hodgson (1991), who in turn cites Neely (1991) in claiming that priming effects in pronunciation tasks are generally smaller than those in LDTs. However, Neely (1991) was actually referring to numerical effects in milliseconds and not to an estimate of effect size such as Cohen's $d .{ }^{4}$ Therefore, an equally plausible alternative explanation is that semantic priming without association is increased by the LDT through the use of a strategic semantic matching process.

However, as was noted by Rosenthal and DiMatteo (2001), several limitations may be associated with conclusions drawn from such a meta-analysis. These possible limitations include (1) nonindependence, meaning that usually more than one experiment is reported from each individual study; (2) publication bias, in which the size of an effect becomes overestimated because only positive effects tend to be published, whereas null results are simply filed away and ignored by researchers; (3) the apples-and-oranges problem, in which studies with different operationalizations of the independent and dependent variables are combined; and (4) garbage in, garbage out (Hunt, 1997), in which both good and bad studies are mixed to derive misleading estimates.

Lucas (2000) clearly did an impressive job of minimizing most of these possible limitations. To reduce the problem of nonindependence, Lucas (2000) reported her results both across experiments and across studies (with $d$ estimates weighted and averaged across experiments within a study). Also, to reduce publication bias, in her group of 26 studies Lucas (2000) included 4 dissertations, 1 master's thesis, and 2 unpublished manuscripts to minimize the overestimation that would usually arise from including only published material. Unfortunately, however, this introduces a new concern in that the methodologies of these studies may not have been as highly scrutinized as those studies appearing in peer-reviewed journals. Finally, to reduce the "apples-and-oranges" problem, Lucas (2000) reported a preliminary analysis in which she examined separately effect sizes from studies using category coordinates, synonyms, antonyms, script relations, functional relations, and perceptual relations. However, because most of these analyses were based on such a small sample of studies (usually fewer than 3), she cautioned against drawing any strong conclusions. A further problem, however, is that one doesn't know to what extent these different stimulus types contributed to the general effect size estimates across the factors of task, SOA, and RP. Thus, the significant Cohen's $d$ estimates might all have been driven either by a certain type of stimulus or, more likely, by interactions in which different types of stimuli produce priming under different tasks or conditions.

Of most importance, however, Lucas (2000) made no attempt to reduce the "garbage in, garbage out" problem of meta-analysis. This is likely due to a desire not to impose any personal bias on the literature. Unfortunately, this can lead to misleading results, since important methodological flaws, such as repeating targets, giving prior study tasks, using degraded targets, or using incorrect baselines, are ignored. Clearly, not all studies are created equal, and potentially important flaws should be taken into consideration when results are interpreted. Because of this limitation, as well as the concerns listed above, the present review consists of a much more indepth look at the individual studies that claim to obtain either pure associative or pure semantic priming. It is hoped that the inclusion of pure associative studies and the present, more careful analysis of pure semantic priming, when combined with Lucas's (2000) more global analysis of pure semantic priming, will provide a clearer overall picture of the evidence for and against both associative and featural priming. 


\section{ASSOCIATIVE PRIMING}

Researchers interested in demonstrating associatively related priming often select stimuli that are semantically unrelated yet are either already associated or become associated only within the experimental context. Because a feature theory should predict a null result in such cases, automatic priming obtained from these items would provide support for association theories over feature theories. However, because highly associated items tend to share semantic relations as well, such evidence is difficult to obtain as researchers are forced to select stimuli containing only a weak to moderate association. (As we will see later, researchers examining "pure semantic" priming have encountered the same problem.) As a way of circumventing this problem, "pure associative" experiments have primarily featured one of four types of stimuli: phrasal associates, episodic associates, mediated associates, and asymmetrical associates. Results from experiments in which each of these types of stimuli have been used are discussed below.

\section{Phrasal Associates}

Hodgson (1991), Williams (1996), and Perea, Gotor, and Nácher (1997) have all examined priming for phrasal associates - that is, words that tend to co-occur in common phrases (e.g., help-wanted). Because these items supposedly become associated through their cooccurrence in language, the assumption is that they share very little semantic overlap. Thus, any priming from these items is supposedly due solely to association strength or lexical co-occurrence frequency. (As was discussed previously, this assumption is suspect, since many of these items, such as spider-web, combine to form a unitary semantic concept.) In LDTs (Experiment 1) and pronunciation tasks (Experiment 3), Hodgson presented participants with each target item four times, with all items presented at SOAs of 500, 83, 150, and $250 \mathrm{msec}$, in that order. In addition, each target was counterbalanced both across and within subjects to appear in the related, the unrelated, or the neutral condition. Each participant thus saw each target in a different condition across the first three SOAs. During the final SOA session, each participant was presented with the same materials seen in Session 2 (the 83-msec SOA session). Unfortunately, because Hodgson combined these effects with those from other item types, such as synonyms, antonyms, and conceptual associates, and examined only the overall priming effect across all six types of pairs, the significance of each individual effect is not known.

In the LDT, Hodgson (1991) found priming of 13, 17, 29, and $21 \mathrm{msec}$ for the 83-, 150-, 250-, and 500-msec SOAs, respectively. In the pronunciation task, these respective priming effects dropped to $5,4,5$, and $5 \mathrm{msec}$. This pattern suggests that the priming obtained in the LDT was due mostly to a strategic backward-checking mechanism rather than to automatic activation. However, because the individual priming effects in both lexical decision and pronunciation were not directly tested, this conclusion is premature. In addition, these items were only weakly associated according to both Hodgson's own norming procedure and the current Nelson, McEvoy, and Schreiber (1999) word association norms. Therefore, any possible priming from these items may be due either to a lack of semantic feature overlap or to a lack of association strength.

Williams (1996) and Perea et al. (1997) also tested priming for other associates that supposedly did not share a semantic relation. In his first experiment, Williams obtained significant priming of $18 \mathrm{msec}$ in a standard pronunciation task and of $22 \mathrm{msec}$ in a pronunciation task in which the target was visually degraded. In a later experiment, Williams replicated his first experiment, finding $21 \mathrm{msec}$ of priming in a standard pronunciation task. Perea et al. used a masked presentation with items displayed for only $67 \mathrm{msec}$ and no interstimulus interval (ISI) between the prime and the target (conditions that clearly should eliminate strategic processing). They found significant priming of $16 \mathrm{msec}$ for these items in an LDT. Moreover, this 16-msec effect was no different from the 18-msec effect obtained from associated pairs that also shared a semantic relation (e.g., coffee-tea).

Although both of these studies appear to provide strong evidence of the importance of associative relations to priming, close inspection of the stimuli used in them reveals a mixture of associate types (see Table 1 ). Many of Williams's (1996) 16 strongly associated phrasal pairs actually represented a variety of semantic relations, including category members (e.g., cat-mouse), antonyms (e.g., black-white), and functional relations (e.g., knifefork). Similarly, Perea et al.'s (1997) stimuli consisted of a mixture of phrasal associates (e.g., spider-web, hockey-ice) along with many functional associates (e.g., rug-floor, hammer-nail) and many property relations (e.g., sheep-wool, camel-hump). In both studies, one would be hard pressed to claim that these types of associates share no semantic relation. Thus, priming from these items could instead be due to feature overlap and, thus, do not aid in differentiating between association and feature theories of semantic memory representation. More research using stimuli that are moderately to strongly associated and contain no semantic feature overlap is clearly needed. However, these items may be difficult or perhaps even impossible to obtain.

\section{Episodic Priming}

Rather than study phrasal associates, some researchers have examined new associations, selecting either items with no preexperimental meanings or ones that initially contained unrelated meanings and became associated during an experimental study phase. For present purposes, the important question concerns whether items related only through association, with no more overlap in semantic features than unrelated controls, would produce automatic priming. 
McKoon and Ratcliff (1979) examined whether recently learned associations could lead to priming. In their experiment, participants studied prime-target items that were either already associated (e.g., green-grass) or not associated (e.g., city-grass). Later, these items were presented one at a time for a speeded lexical decision response (this procedure is henceforth called the continuous LDT procedure). Across their first two experiments, McKoon and Ratcliff (1979) showed equal priming for the preexisting associated items and the newly associated items. Moreover, in their third experiment, McKoon and Ratcliff (1979) demonstrated that this priming was not due to any preexisting relations, since such items did not show priming if they were not paired together during study. McKoon and Ratcliff (1979) concluded that newly associated items can show automatic priming and that these effects are not due to any overlap in meaningful features between the items.

Other researchers since McKoon and Ratcliff (1979) have had difficulty replicating their results (Carroll \& Kirsner, 1982; Dagenbach, Horst, \& Carr, 1990; Durgunoğlu \& Neely, 1987; Neely \& Durgunoğlu, 1985) and have suggested that pure episodic priming may occur only in limited circumstances. For instance, both Carroll and Kirsner (1982) and Neely and Durgunoğlu (1985) failed to obtain pure episodic priming under conditions similar to those used by McKoon and Ratcliff (1979). Durgunoğlu and Neely later noted that McKoon and Ratcliff's (1979) continuous LDT procedure provided a longer SOA than did that of Carroll and Kirsner, who instead presented the prime and the target simultaneously. In addition, Neely and Durgunoğlu included word-nonword pairs in the study phase to guarantee that participants could not respond "word" simply by recalling having seen the prime or target during study. Finally, both Carroll and Kirsner (1982) and Neely and Durgunoğlu (1985) had included preassociated prime-target pairs at test (e.g., minor-major) that had been paired with unrelated items during study (e.g., minor-hold and proud-major). The inclusion of these pairs should prevent participants from strategically utilizing the studied prime word to predict the studied target, since a prime studied with an initially unrelated target could now be followed in the LDT by (1) the same unrelated target, (2) a semantically associated target from a different studied pair, (3) an unstudied unrelated target word, (4) a studied nonword, or (5) an unstudied nonword.

In their attempt to understand these conflicting results, Durgunoğlu and Neely (1987) manipulated(1) whether the SOA was always $900 \mathrm{msec}$ or, instead, randomly varied between 150 and $900 \mathrm{msec}$, (2) whether preexperimentally associated items were studied or unstudied, and (3) whether nonwords were previously studied. Across their four experiments, Durgunoğlu and Neely replicated McKoon and Ratcliff's (1979) episodic priming only under conditions in which the SOA was $900 \mathrm{msec}$ throughout the experiment, studied nonwords were absent at the time of test, and the test contained no preassociated pairs pre- sented in unrelated conditions during study. Durgunoğlu and Neely concluded that episodic priming is most likely to occur when participants can strategically use episodic information (knowing that both words were studied together) to make their decisions. Therefore, although the McKoon and Ratcliff (1979) result can be replicated, it may depend on conditions that favor strategic rather than automatic processing.

Dagenbach et al. (1990) examined the possibility that episodic associates must first receive extensive pairings before activation automatically spreads from one item to the other. In their first and fourth experiments, Dagenbach et al. presented participants with pairs of unrelated words to learn. In their second and third experiments, they had participants learn the definitions of extremely rare words and then learn to associate these words with provided synonyms. Dagenbach et al. found evidence of episodic priming only in their third experiment, in which a small number of extremely rare words were used, the participants were given an extensive 5 weeks of training on these items, and the study sessions emphasized learning the meaning of the items.

This pattern of priming has since been interpreted as providing strong support for feature theories of semantic memory in that newly learned items fail to show automatic priming unless a meaningful relation is established between them (De Mornay Davies, 1998). However, Dagenbach et al. (1990) cautioned against drawing this premature conclusion, noting that it may be more difficult to establish a link between two previously unrelated (known) words than to forge a completely new link. This difficulty could arise because previously known words are already established in a rich semantic structure quite removed from other known, unrelated words. Finally, because of the small number of items used in their experiments, Dagenbach et al. may not have had the power necessary for their $(23-\mathrm{msec})$ episodic priming effect with pure associative study to reach significance. Indeed, although not directly tested, it is unlikely that the $20-\mathrm{msec}$ increase in priming (to $43 \mathrm{msec}$ ) following meaningful study was even significant.

In an attempt to eliminate the problem of associating words with preexisting knowledge structures, Hayes and Bissett (1998) utilized a derived stimulus relations procedure, in which participants were asked to figure out which foreign words "go together" (they were actually given nonwords with no preexisting meanings). In their experiment, Hayes and Bissett presented participants with a target nonword (labeled an "A item") with three other nonwords listed below it (labeled "B items"). The participants' task was to figure out which "foreign" words were related by selecting the correct nonword from the three nonwords listed below the target (the correct B item), thus forming an initial A-B association. In the second phase, Hayes and Bissett presented the participants with the original A items and had them form associations with new $\mathrm{C}$ items. In the final phase, they gave their participants an LDT in which they had to decide whether two letter strings were both for- 
eign words (studied during Phases 1 and 2) or one or both were nonwords. Hayes and Bissett found that the participants were faster to respond that both letter strings were words if they had been directly paired together during training. Thus, nonwords, which presumably have no meaning, can produce priming if an episodic association can be established during the experiment.

Recently, Pecher and Raaijmakers (1999) found significant priming from initially unrelated items that were paired together during the study phase relative to unrelated items not paired together during study. However, Pecher and Raaijmakers did not find priming for preassociated items when they were paired together relative to when they were not paired together during study, suggesting that such items receive little benefit of additional intraexperimental pairings. Moreover, although the new associations facilitated performance in lexical decision, no beneficial effects of study were found for a perceptual identification task in which participants were presented with a prime followed by a visually degraded target shown for gradually increasing durations until an identification response was given. Pecher and Raaijmakers interpreted this effect as indicating that new episodic associations are context specific and unlikely to transfer to a new task. One may therefore question the extent to which these effects are truly automatic.

\section{Mediated Priming}

The concept of spreading activation in Collins and Loftus's (1975) model allows for a particularly useful approach to differentiating between association and feature accounts of semantic priming. According to spreading activation models, when a concept (e.g., LION) is activated, this activation spreads not only to directly associated concepts (e.g., TIGER), but also to indirectly related concepts (e.g., STRIPES). Thus, although LION and STRIPES share little to no overlap in semantic features, priming should occur for these mediated items relative to unrelated control pairs. In Table 2, the results from 22 experiments on mediated priming are presented. Of these 22 experiments, 7 included both direct and mediated pairs within the same participants, 10 included only mediated pairs, and 5 included both types of lists across participants. The experiments listed in this table are organized by the type of task used (standard LDT, twoword LDT, continuous LDT, and pronunciation) and the list context (direct pairs + mediated pairs or mediated pairs only).

De Groot (1983) conducted a series of experiments using the standard LDT to examine priming for both direct (e.g., cow-milk) and mediated (e.g., bull-milk) associates. In contrast with predictions based on spreading activation, de Groot (1983) consistently found priming only for direct associates and not for mediated pairs. On the basis of the results of seven experiments, she concluded that, contrary to association model predictions, activation does not spread across multiple links in se- mantic memory. However, de Groot's (1983) conclusions were based on a comparison of priming effects with a neutral baseline (e.g., the word blank repeated over all neutral trials). Jonides and Mack (1984) have argued that repeated neutral items do not provide an adequate baseline for priming experiments. Table 2 shows that if de Groot (1983, Experiments 1-4) had instead compared the related condition with her unrelated condition, she would have reported a 43-msec direct priming effect in Experiment 1 and mediated priming effects of 19, 18, 32, and $35 \mathrm{msec}$ in Experiments 1, 2, 3, and 4, respectively. An examination of the studies in Table 2 that contained both neutral and unrelated conditions in the standard LDT (one by de Groot, 1983, and two by Shelton \& Martin, 1992) does seem to show that mediated priming effects are larger when computed from an unrelated baseline than when computed from a neutral baseline. This baseline-dependent numerical difference in priming appears to occur in the standard LDT, but notice in Table 2 that this difference in priming does not appear in the other tasks.

Balota and Lorch (1986) identified two additional reasons not to accept de Groot's (1983) null result as evidence against mediated priming. First, because the amount of facilitation is predicted by network theories to be smaller than that found for direct pairs, and given the relatively short $26 \mathrm{msec}$ of priming obtained for direct pairs (relative to de Groot's, 1983, neutral prime), she may not have had the power necessary to detect any mediated priming. Second, as was discussed earlier, performance on the standard LDT often involves an additional semantic matching process in which participants utilize prime-target relatedness to facilitate their "word"/"nonword" responses. This strategy should facilitate priming for directly associated targets (e.g., tiger-stripes) but impair responding to unrelated targets (e.g.,fence-stripes) or mediated targets (e.g., lion-stripes), since the absence of a direct relation in the latter pairs would bias a "nonword" response. It is therefore possible that any facilitation due to spreading activation in de Groot's (1983) experiment was eliminated by this semantic matching process. The apparent baseline effect seen in Table 2 is consistent with the use of this type of strategic semantic matching process. Also in accordance with this interpretation, Balota and Lorch obtained significant mediated priming in a pronunciation task while replicating de Groot's (1983) null result in lexical decision.

Following Balota and Lorch (1986), several researchers have examined mediated priming by varying either the type of task or the list context in order to reduce any strategic processing. For instance, McNamara and Altarriba (1988), McKoon and Ratcliff (1992), Sayette, Hufford, and Thorson (1996), and Livesay and Burgess (1998) all found significant mediated priming in the LDT when the stimulus list contained only mediated and unrelated items (but see Chwilla, Kolk, \& Mulder, 2000, for a different finding). The use of such lists eliminates any noticeable 
Table 2

Priming Effects on Reaction Time (in Milliseconds) for Directly Related (Direct) and Mediated (Med) Items in Experiments Using a Neutral Baseline, an Unrelated Baseline, or Both

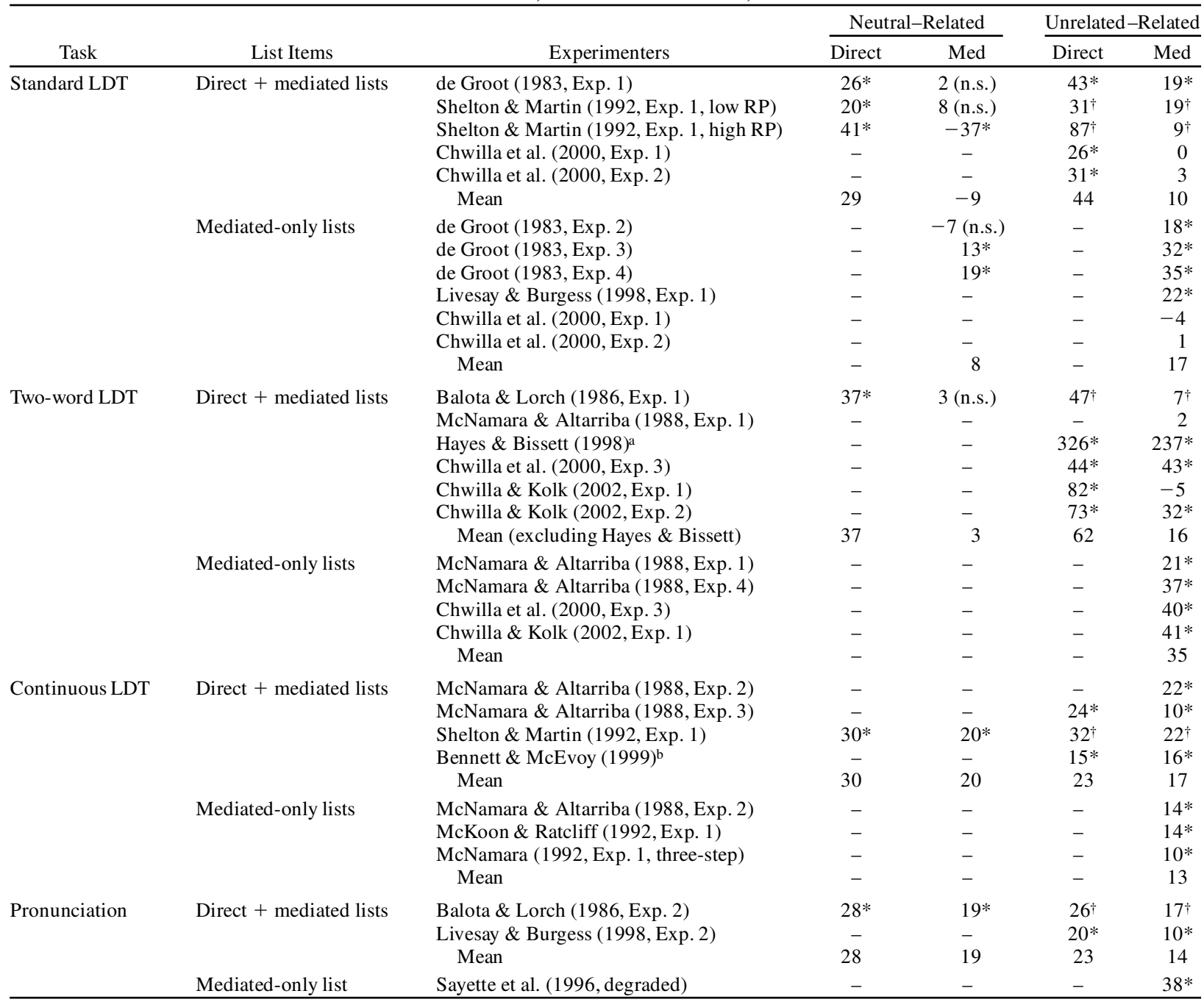

Note-LDT, lexical-decision task; two-word, respond to two targets simultaneously; continuous LDT, respond to both primes and targets in lexical decision; degraded, visually degraded target; n.s., not significant. $* p<.05$. Contrast not tested for significance. anew associates formed from nonwords were used. bData from their young participants only.

relation between the prime and the target and presumably prevents participants from engaging in any strategic semantic matching process.

One seemingly anomalous result listed in Table 2 is Chwilla and Kolk's (2002) finding of a nonsignificant $-5 \mathrm{msec}$ of mediated priming in their first experiment, yet a significant $32-\mathrm{msec}$ mediated priming effect in their second experiment using the same task. However, the participants in their second experiment first made lexical decisions on a list consisting entirely of seemingly unrelated items. Chwilla and Kolk suggested that the unrelated items in the first list may have discouraged the use of strategies that normally function to increase direct priming yet eliminate mediated priming.
McNamara and Altarriba (1988) used a continuous LDT procedure (see Davelaar \& Coltheart, 1975) in which participants responded to every letter string presented. The authors argued that using this procedure should eliminate semantic matching because failure to detect a relation with the previous word would provide no information regarding the lexicality of the current letter string. By eliminating semantic matching in this way, McNamara and Altarriba reasoned that they could present participants with both direct and mediated associates and compare the relative priming for each. Using this procedure, they found significant priming for both direct and mediated pairs. Since McNamara and Altarriba, several researchers have adopted this procedure as a way to re- 
duce conscious strategies and examine more automatic priming. Using this procedure, McNamara (1992), McKoon and Ratcliff (1992), Shelton and Martin (1992), and Bennett and McEvoy (1999) all found significant mediated priming. McNamara even found small but significant priming across two mediated items (e.g., manestripes). 5

Inspection of Table 2 suggests that McNamara and Altarriba (1988) were correct in their assumption that the continuous LDT eliminates strategic processing, since performance on this task does not appear to be influenced by either the type of baseline used or the list context. (However, McNamara and Altarriba were the only researchers who actually manipulated list context.) Importantly, these results demonstrate that, when care is taken to eliminate strategic processing, mediated priming consistently emerges across studies. ${ }^{6}$ These results provide evidence of the process of spreading activation, because the mediated pairs share no direct association. Moreover, these results support the idea of priming based on association, since mediated pairs presumably share no more semantic features than do their unrelated controls.

McKoon and Ratcliff (1992), however, argued that these results do not provide evidence of spreading activation. Instead, they argued that mediated primes and targets actually share a weak direct relation that is undetected in free association norms. To demonstrate the insensitivity of association norms to weak semantic relations, McKoon and Ratcliff (1992) selected items that they intuitively thought would lead to priming yet had no identifiable direct or mediated association (e.g., deergrain), and they found priming from these items to be equal to that obtained from mediated pairs identified through association norms. In accounting for their priming effects, McKoon and Ratcliff (1992) appealed to their compound cue theory of priming, according to which primes and targets form a compound cue in shortterm memory, which leads to a greater feeling of familiarity and a faster lexical decision response. McKoon and Ratcliff (1992) proposed that priming researchers should use measures of the frequency at which two words co-occur in language rather than association norms, since the compounds formed by the former items should be highly familiar. In support of this claim, McKoon and Ratcliff (1992, Experiment 3) obtained significant priming for items high in lexical co-occurrence (e.g., hospital-baby), but not for low co-occurrence items (e.g., room-baby), suggesting that it is this lexical co-occurrence of items that leads to mediated priming.

There are at least three findings, however, that present problems for McKoon and Ratcliff's (1992) argument. First, Balota and Lorch (1986) and McNamara (1992) relied on more than just association norms to ensure that their items were not directly related. In norming their items, Balota and Lorch had participants rate the degree of association for each pair. Although the mediated items were rated as slightly more associated than the unrelated items, there was no correlation between the ratings given to the mediated pairs and the size of their priming effects $(r=-.017)$. Moreover, McNamara separated his mediated items into those that might plausibly share a semantic relation and those that do not. The priming effects obtained for the potentially related items and the unrelated items were 8 and $10 \mathrm{msec}$, respectively, suggesting that the semantic relation between the items is unimportant. Second, Livesay and Burgess (1998) calculated co-occurrence frequencies for Balota and Lorch's items and found no relation between the strength of priming and lexical co-occurrence. The third argument against McKoon and Ratcliff's (1992) claims comes from the experiment by Hayes and Bissett (1998) described earlier. Of interest, Hayes and Bissett found significant priming not only from the direct $\mathrm{A}-\mathrm{B}$ and $\mathrm{A}-\mathrm{C}$ pairs formed during training, but also from the $\mathrm{B}-\mathrm{C}$ pairs. This finding is important, because the $\mathrm{B}$ and $\mathrm{C}$ items were never directly paired during study; thus, any associations between them would have to be mediated through the A items (although this association could potentially have been made consciously during the A-C training). When combined with the earlier results, these data provide converging evidence that pure mediated priming is not due to any small direct relation between the items.

\section{Asymmetrical Priming}

Another approach to testing the concept of spreading activation is to use items that are associatively related in one direction only. For example, people given the item stork in a free association task are likely to generate the associate baby. However, those given the item baby are highly unlikely to generate the word stork as an associate. This difference in associative strength between pairs presented in the forward versus the backward direction is predicted by spreading activation theories. According to the fan effect theory (Anderson, 1983; Anderson \& Bower, 1973), a high-frequency word such as baby will activate a large number of associated concepts, such as MOTHER, CRIES, and CHILD. However, the amount of activation will be dispersed across all these different paths, reducing the activation of any one concept. In contrast, a low-frequency word such as stork is limited to only a few links in semantic memory, such as BABY and BIRD. As a result, these concepts will receive a majority of the activation spreading from stork, leading to greater activation. If one assumes that asymmetrically associated items such as baby-stork share the same number of features regardless of presentation order, a feature-based model of semantic memory would predict equal priming effects for both directions of presentation. In contrast, association theories predict that one should find much greater priming effects in the forward than in the backward direction.

In Table 3, the results of nine experiments in which backward priming was examined are presented. ${ }^{7}$ In most of these studies (Kahan, Neely, \& Forsythe, 1999; Koriat, 1981; Peterson \& Simpson, 1989; Seidenberg, Wa- 
Table 3

Priming Effects on Reaction Time (in Milliseconds) for Forward and Backward Associates in Nine Experiments

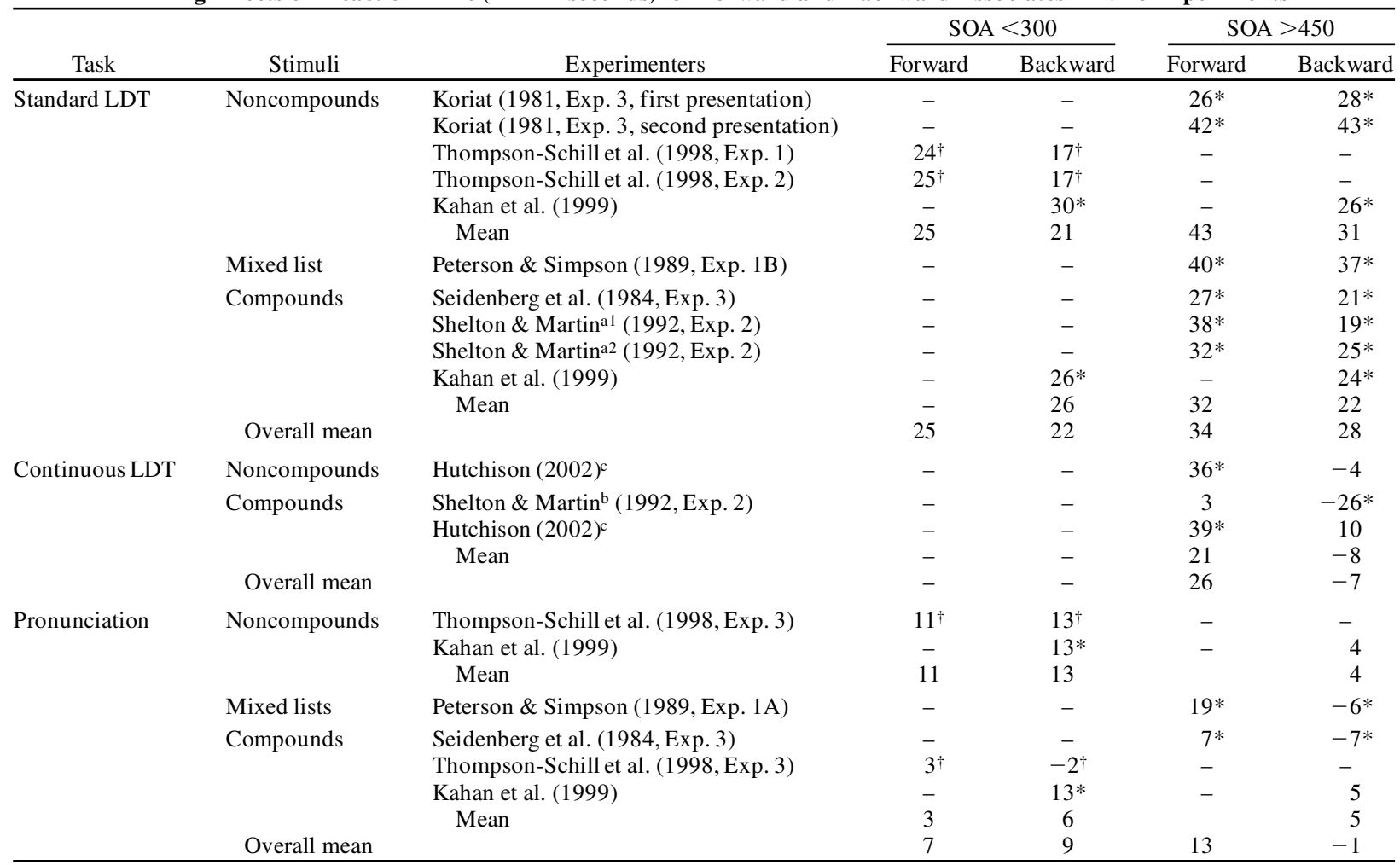

Note-All priming effects were computed relative to an unrelated baseline. Standard LDT, standard lexical decision task; continuous LDT, separate responses to prime and target. ${ }^{*} p<.05$. Contrast not tested. ${ }^{a 1}$ Low (.24) relatedness proportion and low (.43) nonword ratio. a2 High (.76) relatedness proportion and high (.67) nonword ratio. ${ }^{b}$ Response-stimulus interval $=500 \mathrm{msec} . \quad{ }^{\mathrm{c}}$ Response-stimulus interval $=600 \mathrm{msec}$ and interstimulus interval $=2,000 \mathrm{msec}$.

ters, Sanders, \& Langer, 1984; Shelton \& Martin, 1992; Thompson-Schill, Kurtz, \& Gabrieli, 1998), a standard LDT was utilized, although in some either a continuous LDT (Hutchison, 2002; Shelton \& Martin, 1992) or a pronunciation task (Kahan et al., 1999; Peterson \& Simpson, 1989; Seidenberg et al., 1984; ThompsonSchill et al., 1998) was utilized. In addition, all of these studies used asymmetrically associated noncompound pairs (e.g., stork-baby), prime-target pairs that form a compound word when combined (e.g., lip-stick), or both.

Koriat (1981) was the first researcher to explicitly test the assumption that automatic priming is based purely on a directional flow of activation from the prime concept to the target concept. However, Koriat's data failed to support this prediction. Using the standard LDT and an SOA of $650 \mathrm{msec}$, Koriat obtained equal priming for forward pairs (e.g., stork-baby) and backward pairs (e.g., baby-stork) relative to their unrelated baseline conditions (e.g., fence-baby and tree-stork, respectively). Thus, contrary to predictions based on spreading activation, the direction of the association did not influence the amount of priming. As is shown in Table 3, Ko- riat's finding of significant backward priming using the standard LDT and a long SOA has been replicated by Seidenberg et al. (1984), Peterson and Simpson (1989), Shelton and Martin (1992), and Kahan et al. (1999). Moreover, averaged across all experiments using the standard LDT and a long SOA, the size of the backwardpriming effect $(M=28 \mathrm{msec})$ is comparable to the size of the forward-priming effect $(M=34 \mathrm{msec})$, and in every experiment the two priming effects were statistically equivalent.

One possible explanation is that priming depends solely or primarily on the feature overlap between the prime and the target. This overlap in features could produce priming irrespective of the order in which the items are presented. ${ }^{8}$ The second possibility is that backward priming is due solely to conscious strategies engaged during the standard LDT, particularly strategic semantic matching. Whereas this process should reduce or eliminate priming from mediated pairs (since they would be seen as unrelated), it should greatly enhance priming from backward-related or symmetrically related pairs (since a relationship would be detected). This "strategic" explanation therefore predicts priming for only forward 
or symmetrical pairs in tasks such as pronunciation tasks or continuous LDT, both of which are less dependent than the standard LDT on semantic matching.

Initial results from Seidenberg et al. (1984) support the semantic matching explanation of backward priming. Seidenberg et al. replicated the work of Koriat (1981) in using the standard LDT, yet found only forward priming effects when they switched to pronunciation tasks. Inspection of the pronunciation experiments in the bottom half of Table 3 reveals that, with an SOA over $450 \mathrm{msec}$, priming occurs for forward-related pairs $(M=13 \mathrm{msec})$ but not for backward-related pairs $(M=-1 \mathrm{msec})$. These results from pronunciation tasks at long SOAs are consistent with association theories predicting spreading activation and are inconsistent with feature-based models that rely more on feature overlap between the two components of prime-target pairs.

In addition, using a continuous target procedure thought to eliminate conscious strategies, Shelton and Martin (1992) found significant inhibition for backwardrelated pairs. However, given their lack of significant priming for forward-related pairs, Shelton and Martin's backward-related inhibition result is difficult to interpret. Hutchison (2002) also utilized a continuous LDT and found significant forward priming from both compound and noncompound items but no effects for either type of item when presented in the backward direction. However, Hutchison's procedure included a 2-sec interval between trials, making it unclear whether participants might have temporally grouped the primes and targets together. More research into this task is therefore needed before any conclusions regarding semantic memory representation can be drawn.

Whereas the data based on a long SOA support spreading activation, those based on a short SOA instead provide evidence of feature overlap. Significant backwardpriming effects have been obtained in pronunciation for both compounds (e.g., stick-lip) and noncompounds (e.g., baby-stork) when a brief SOA $(<300 \mathrm{msec})$ is used. Because the pronunciation task is presumably exempt from semantic matching processes, Thompson-Schill et al. (1998) argued that their backward priming obtained at a 200-msec SOA was due purely to semantic (featural) similarity between their items. In accordance with this interpretation, Thompson-Schill et al. found backward priming in both directions from their noncompound items that supposedly shared a semantic relationship(e.g., stem-flower), but no priming in either direction from their compound items that supposedly did not share any semantic relation (e.g., lip-stick). Thus, these data suggest an initial automatic priming component (attributed to feature overlap) that occurs at short SOAs but is overcome by conscious, association-based expectancies at longer SOAs.

Unfortunately, there are three reasons to question this conclusion. The first is that Kahan et al. (1999) obtained significant backward priming for both compounds and noncompounds using a pronunciation task and a 150- msec SOA. Thus, automatic backward priming in the pronunciation task occurs even for weakly associated items with very little semantic overlap. The second reason concerns Thompson-Schill et al.'s (1998) stimuli. Although they derived their semantically unrelated compound stimuli (e.g., lip-stick) from the "nonassociated" items used by Seidenberg et al. (1984), Thompson-Schill et al. used their own norming technique to derive their semantically related noncompounds (in which participants were asked to generate four responses to each item). If the target was generated as a first associate, it was given a score of 4; if it was generated as a second associate it was given a score of 3 , and so on. Overall, for their "nonassociated" semantically related items, the forward pairs received an average score of 1.63 (meaning that, on average, the target was around the third or fourth response) and the backward pairs received an average score of 0.35 (meaning that, on average, the target was either the fourth response or not given as one of the four). However, when these forward and backward association strengths are calculated according to the Nelson et al. (1999) association norms, the mean forward and backward association strengths for their compound items (e.g., lip-stick) are $2 \%$ (range $=0 \%-8 \%$ ) and $0 \%$ (range $=$ $0 \%-.01 \%$ ), respectively, whereas the mean forward and backward association strengths for their noncompound items (e.g., stem-flower) are $41 \%$ (range $=15 \%-88 \%$ ) and $3 \%$ (range $=0 \%-26 \%$ ), respectively. Thus, ThompsonSchill et al. confounded semantic overlap with association strength, since their semantic noncompound items were more strongly associated in both the forward and backward directions than were their nonsemantic compound items. Finally, as was discussed previously, the argument that compound words such as lipstick are not semantically related is extremely weak, as people undoubtedly have a representation for the concept LIPSTICK as well as for some of its perceptual properties (e.g., red), functional uses (e.g., apply color), and even conceptual relatives (e.g., MASCARA).

\section{Summary of "Pure Associative" Priming}

In this section, experiments on priming for phrasal associates, episodic associates, mediated associates, and asymmetrical associates have been examined to address the question of whether a purely associative relation between stimuli is sufficient to produce automatic priming or whether, instead, some overlap in semantic features is necessary. With priming from phrasal associates having been tested directly in only three studies, the results are still unclear. Whereas Williams (1996) and Perea et al. (1997) obtained significant results using a pronunciation task and a masked LDT, respectively, Hodgson (1991) found priming only in the standard LDT, suggesting that the effect is due to some postlexical process. However, methodological problems make it difficult to draw firm conclusions from Hodgson's experiments. Also, an examination of William's and Perea et al.'s stimuli actually reveals many semantic relations. 
Much more research has been conducted on items associated in a purely experimental context. Although McKoon and Ratcliff (1979) originally claimed to find significant automatic priming for these items, this effect has been difficult to replicate. By systematically manipulating factors that have varied across laboratories, Durgunoğlu and Neely (1987) reported episodic priming only when the SOA was sufficiently long to promote strategic processing and participants could strategically use their episodic memory for the pairs in making their lexical decisions. Dagenbach et al. (1990) later found significant priming for episodic items; however, they used a small number of extremely rare words, gave participants an extensive 5-week training period, and emphasized learning the meanings of the items. It is not clear which of these factors led to their significant effects. More recently, experiments by Hayes and Bissett (1998) using nonwords and by Pecher and Raaijmakers (1999) have provided further support for episodic priming in the LDT. However, Pecher and Raaijmakers showed that this effect did not transfer to a new task, calling into question whether the episodic effects from previously unrelated words were dependent on task-specific strategies, as was suggested by Neely and Durgunoğlu (1985).

Much stronger evidence of associative priming comes from experiments in which mediated priming (e.g., from lion to stripes) was examined. Importantly, these items share neither a stronger direct association nor more feature overlap than their unrelated controls. Priming from these items is almost certainly automatic, since strategic mechanisms such as expectancy generation and/or semantic matching should work (and indeed have worked) against obtaining priming for these items. By carefully designing experiments to reduce or eliminate conscious strategies, Balota and Lorch (1986), McNamara and Altarriba (1988), McKoon and Ratcliff (1992), Sayette et al. (1996), Livesay and Burgess (1998), and Chwilla and Kolk (2002) have all found significant mediated priming effects.

Results from backward priming experiments in which a long SOA between prime and target presentation was used appeared to provide evidence of association theories of semantic priming. However, results from experiments in which a short SOA was used contradict this conclusion. As for the importance of feature overlap, the results are ambiguous. The cause of the forward and backward priming effects observed at the short SOAs in the pronunciation task is unknown, and more research is necessary to explain these effects.

However, there is reason to question the logic of even using asymmetrical priming as a tool for testing between association versus feature theories. Tversky (1977) and Tversky and Gati (1982) argued that the perceived similarity of one item to another is not always symmetrical but is instead influenced by the order in which they are presented. In particular, the perceived similarity is greater if the item containing more distinctive features (i.e., the less prototypical item) is listed first (see Rosch, 1973, 1975, for a similar argument). For instance, the pair leopard-tiger would be rated as more similar than the pair tiger-leopard, presumably because a leopard is viewed as a variation of a tiger, but a tiger is not viewed as a variation of a leopard. Indeed, examining the noncompound stimuli used in most asymmetrical priming experiments, a large portion of the items (e.g., mint-candy, lizard-snake, path-road) share this type of variant-prototype relation. Similarly, many other pairs contain a specific-general relation in which the target word is a general category, general property, or general function and the prime is an example of a member of the category, an item having the property, or an item that performs the function, respectively (e.g., eagle-bird, stove-hot, scissors-cut). As a result, the pair eagle-bird would be rated as more similar than bird-eagle. Taken together, these arguments suggest that asymmetrical semantic priming would provide support for both association and feature theories of semantic priming.

\section{SEMANTIC PRIMING}

Like researchers testing associative priming, those examining semantic feature priming have either (1) selected items that share semantic features yet contain little to no association or (2) compared priming for associated items that share semantic features with priming for those that do not. In both cases, a finding of increased priming for items with feature overlap supposedly lends support to feature-based models of semantic priming.

In Tables 4-8, the results of 24 studies examining priming from different types of "nonassociated" semantic relations are presented. This list is quite distinct from that of the 26 studies reported by Lucas (2000). The reason for which many of Lucas's (2000) studies were excluded was that most of our available evidence for automatic versus strategic priming mechanisms comes from research on young to middle-aged adults using central primes and targets. To properly evaluate semantic priming and to make comparisons with the associative priming studies described in the previous section, these conditions must be met. For the same reason, semantic feature priming studies using auditory primes and/or targets will be discussed in a separate section following the section on those using visually presented stimuli. Surely, if featural priming cannot be seen under these "normal" experimental conditions, its automaticity must be called into question. For instance, under auditory prime presentation conditions, it is unclear whether participants would utilize semantic matching or some other integration process, since an auditory trace of a prime should still be available in echoic memory during the presentation of a target. (A further discussion of this issue is given in the section on auditory priming.)

The Lucas (2000) studies excluded from the present review therefore include one study with elderly participants, two studies with laterally presented primes and/or targets, one study (Thompson-Schill et al., 1998) already discussed in the previous section, and six studies not published in peer-reviewed journals. In addition, the 
present review includes nine published studies that were not included in Lucas (2000) due to either a lack of variability information from which to calculate an effect size or publication after the year 2000. Finally, like Lucas (2000), the present review does not consider results from studies in which a semantic categorization task was used, because there is considerable doubt as to whether the results from such a task reflect anything about the underlying representations of these items in semantic memory (de Groot, 1990; Lucas, 2000). The major problem is that categorization tasks confound response congruency with semantic relatedness in that related pairs (e.g., lion-tiger in an "animate/inanimate" decision) are associated with the same response, whereas unrelated primes (e.g., window-tiger) are associated with different responses. Importantly, this response congruency should speed up reaction times to related targets even if the prime has no effect on lexical access to the target. (See Wentura, 2000, for a similar argument against experiments claiming to show automatic "evaluative" priming.) ${ }^{9}$

\section{Types of Semantic Relations}

As is demonstrated in Table 1, simple inspection of most association norms reveals many different types of semantic relations between words. These relations include synonyms, antonyms, property relations, category members, super- and subordinate relations, functional relations, and script relations. Of importance, although at least some of each type of relation is included in most association norms, only the category members and superordinate and subordinate relations have traditionally been identified as semantic, whereas the remaining types of relations have typically been labeled "associative."

In order to confirm the association strength assigned by the authors to their stimulus pairs, I have calculated the forward and backward association strengths of the items in each study using the Nelson et al. (1999) norms. ${ }^{10}$ In this analysis, the association strength was defined as one of the following: (1) no association, with an average strength of less than $1 \%$ in both the forward and backward directions; (2) weak association, with an average strength between $1 \%$ and $10 \%$; (3) moderate association, with an average strength between $10 \%$ and $20 \%$; and (4) strong association, with an average strength of greater than $20 \%$. Therefore, according to the present classification, a pair would be classified as weakly associated if between $1 \%$ and $10 \%$ of the population would give the target item as their primary response to the prime. This is preferable to simply relying on an individual experimenter's own norms, not only because it allows for both forward and backward estimates but also because the Nelson et al. values were normed on over 6,000 participants, making for more reliable estimates. (It makes no sense for researchers to claim that items have a $0 \%$ association, meaning that 0 out of 100 people would give the target as a response to the prime, if the norms were generated from only 40-50 people.) One may claim that this is still too conservative a measure of association strength, since it focuses only on the primary response and does not take into consideration whether or not the target would be given as a second, third, or even a fourth associate. However, even with this conservative criterion, items occasionally classified by the original experimenters as having no association were found to have weak associations (Frenck-Mestre \& Bueno, 1999; Moss et al. 1995; Perea et al., 1997), and some items classified as weak actually had moderate associations (Williams, 1996). (Note that this discrepancy stems primarily from the works of authors who failed to account for backward target-to-prime associations.)

Use of the Nelson et al. (1999) standardized norms also allowed for the comparison of association strengths among different sets of items claimed to vary only in semantic feature overlap. For instance, Hines, Czerwinski, Sawyer, and Dwyer (1986), De Mornay Davies (1998), and Thompson-Schill et al. (1998) each concluded that priming was based purely on semantic feature overlap based, in turn, on the finding of significant associative priming only from items sharing a semantic relation with the target. However, inspection of the stimuli used in each of these three experiments reveals that, in each study, the semantic + associated items were all more strongly associated than the associated-only items (all $p s<.05$ ), making it impossible to determine whether the obtained differences in priming were due to differences in semantic relatedness (as was claimed by the authors) or, instead, to differences in association strength.

\section{Category Coordinates}

Table 4 presents the results of experiments in which priming from categorically related pairs was examined. The experiments in this table are organized according to the type of task used (standard LDT, masked LDT, continuous LDT, standard pronunciation, and pronunciation with a visually degraded target) and the SOA between the presentation of the prime and the presentation of the target (greater than or less than $300 \mathrm{msec}$ ), on the assumption that longer SOAs permit greater contributions of conscious processing.

As can be seen, there is great variability in priming across the different tasks employed. Large priming effects have consistently been reported by experimenters using the standard LDT. In fact, significant (though much smaller) effects have been reported by both Shelton and Martin (1992) and Williams (1996) despite the absence of association in their stimuli. In addition, using a masked LDT, in which the primes were preceded by a forward mask (e.g., \#\#\#\#\#) briefly (i.e., for 66-166 msec) presented, Perea and Rosa (2002, Experiment 2) reported a significant $27-\mathrm{msec}$ priming effect from their "nonassociated" items, arguing that priming from such items is automatic. However, there are two potential problems with this conclusion. First, in an earlier experiment in which only 66-msec masked primes were used, Perea et al. (1997) found priming only when the items were strongly associated $(18 \mathrm{msec})$, but not when they 
Table 4

Priming Effects in Reaction Time (in Milliseconds) for Category Members Sharing a Strong ( $>.2)$, a Moderate ( $>$.10), a Weak (>.01), or No (<.01) Association According to the Nelson et al. (1999) Association Norms

\begin{tabular}{|c|c|c|c|c|c|c|}
\hline \multirow[b]{2}{*}{ Task } & \multirow[b]{2}{*}{ SOA } & \multirow[b]{2}{*}{ Experimenters } & \multicolumn{4}{|c|}{ Strength of Association } \\
\hline & & & Strong & Moderate & Weak & None \\
\hline \multirow[t]{9}{*}{ Standard LDT } & \multirow[t]{5}{*}{$>300 \mathrm{msec}$} & Lupker $(1984$, Exp. 5) & - & - & $26^{*}$ & - \\
\hline & & Lupker (1984, Exp. 6) & $46^{*}$ & - & - & - \\
\hline & & Shelton \& Martin (1992, Exp. 3A) & $42 *$ & - & - & $34 *$ \\
\hline & & Shelton \& Martin (1992, Exp. 3B) & $36^{*}$ & - & - & $34 *$ \\
\hline & & Mean & 41 & - & 21 & 34 \\
\hline & \multirow{4}{*}{$<300 \mathrm{msec}$} & Williams (1996, Exp. 3)b & - & $39 *$ & - & - \\
\hline & & Williams (1996, Exp. 4) ${ }^{b}$ & - & - & - & $16^{*}$ \\
\hline & & McRae \& Boisvert (1998, Exp. 1A) & - & - & $47 *$ & - \\
\hline & & Mean & - & 39 & 34 & 16 \\
\hline \multirow[t]{2}{*}{ Masked LDT } & \multirow[t]{2}{*}{$<300 \mathrm{msec}$} & Perea et al. $(1997)^{b}$ & $18^{*}$ & - & 6 & - \\
\hline & & Perea \& Rosa (2002, Exp. 1) $)^{b, c}$ & $35^{*}$ & - & - & - \\
\hline \multirow{3}{*}{ Continuous-target LDT } & \multirow{3}{*}{$>300 \mathrm{msec}$} & Moss et al. (1995, Exp. 3) & $26^{\dagger}$ & - & $-4^{\dagger}$ & - \\
\hline & & De Mornay Davies (1998, Exp. 1) & $32 *$ & - & - & - \\
\hline & & Mean & 32 & - & -4 & -11 \\
\hline \multirow[t]{8}{*}{ Standard pronunciation } & \multirow[t]{6}{*}{$>300 \mathrm{msec}$} & Lupker (1984, Exp. 2) & - & - & $7 *$ & - \\
\hline & & Lupker (1984, Exp. 4) & $19 *$ & - & - & - \\
\hline & & Hines et al. $(1986$, Exp. 4) d,e 1 & $-10^{\dagger}$ & - & $-2 \dagger$ & - \\
\hline & & Hines et al. $(1986$, Exp. 4) d,e2 & $7^{\dagger}$ & - & $18^{\dagger}$ & - \\
\hline & & Hodgson $(1991$, Exp. 3) a & - & - & $5^{\dagger}$ & - \\
\hline & & Mean & 5 & - & 7 & - \\
\hline & \multirow[t]{2}{*}{$<300 \mathrm{msec}$} & Lupker (1984, Exp. 3) & - & - & $6^{*}$ & - \\
\hline & & Hodgson $(1991, \text { Exp. } 3)^{\mathrm{a}}$ & - & - & $5 \dagger$ & - \\
\hline
\end{tabular}

Note-All priming effects were computed relative to an unrelated baseline. Standard LDT, single target preceded by prime word; continuous LDT, respond to both primes and targets. $*_{p}<.05$. Contrast not tested. aParticipants responded to the same items over four SOA conditions. bAll primes were masked. ${ }^{\mathrm{c}}$ Association strengths were computed from Algarabel et al. (1988) norms. ${ }^{\mathrm{d}}$ Each prime was presented 12 times. ${ }^{\mathrm{e}} \mathrm{D}$ Data from overall "fast" participants only. $\quad$ e2Data from overall "slow" participants only. ${ }^{\mathrm{fl}}$ A mildly degraded target was given. $\quad$ f2 A severely degraded target was given.

were weakly associated $(6 \mathrm{msec})$. (On the basis of this pattern, Perea and Rosa argued that automatic semantic activation takes at least around $80 \mathrm{msec}$ to accrue.) A second problem is that Perea and Rosa considered only forward association strength when defining their stimuli as nonassociated or perhaps "weakly associated at most" (p. 185). It is possible, however, that these stimuli could contain backward associations. Unfortunately, because their stimuli were taken from Spanish norms (Algarabel, Ruiz, \& Sanmartín, 1988), use of the Nelson et al. (1999) norms for comparison purposes is not completely warranted, since word association responses are much less reliable across languages (Lambert \& Moore, 1966; Rosenzweig, 1970). However, the translations provided do suggest a weak association in the forward direction
(.04) and a moderate association in the backward direction (.11). Whether these norms accurately reflect associations in Spanish remains to be seen. However, the claim that such priming could indeed reflect backward checking rather than semantic activation is also consistent with Perea and Rosa's finding of masked priming only when items were presented for over $80 \mathrm{msec}$ (and are thus clearly visible). Therefore, these masked priming effects do not yet provide strong evidence of feature overlap, rather than association, in producing priming.

A quite different pattern takes shape in experiments in which either the continuous LDT or pronunciation tasks were used. For the strongly associated items, experimenters using the continuous LDT continue to obtain significant priming of around $32 \mathrm{msec}$. However, these 
effects are eliminated for stimuli containing little to no association. For instance, although Moss et al. (1995) appeared to find overall priming for categorical items in a continuous LDT, this was due almost entirely to their highly associated pairs. When only weakly associated pairs were presented to participants, Moss et al. (1995) obtained a nonsignificant $-4 \mathrm{msec}$ of priming. Under similar conditions, Shelton and Martin (1992) observed an average nonsignificant $-10.5 \mathrm{msec}$ of priming for categorical items and an average significant $35 \mathrm{msec}$ of priming for items sharing a semantic + associative relation. Partly on the basis of this pattern of results, and because it has been suggested that the continuous LDT taps purely automatic priming, Shelton and Martin concluded that pure semantic priming results primarily from strategic processing, whereas automatic priming occurs only for word pairs that are associated.

Note in Table 4 that priming from categorically related items almost completely disappears when one uses a standard pronunciation procedure. Lupker (1984) did find small (6-7-msec) amounts of priming for his nonassociated stimuli; however, he pointed out that in none of his experiments was the effect significant by items, suggesting that the observed priming may have been due to a few associated items in a list. Although he found more priming using the standard LDT, Lupker argued that this was due to participants' use of "postlexical" strategies. On the basis of his finding that, across tasks, there was more priming for associated than for nonassociated categorical items and that priming for categorical + associative items was no greater than priming for associative items alone, Lupker concluded that association alone produces automatic semantic priming and that the degree of semantic feature overlap is unimportant. ${ }^{11}$ Instead, both Lupker (1984) and Shelton and Martin (1992) suggested that automatic priming occurs primarily through the type of intralexical connections between associated words originally proposed by Fodor (1983).

Whereas Lupker (1984) and Shelton and Martin (1992) reported no automatic priming for categorical items, Hines et al. (1986) and Williams (1996) drew the opposite conclusion from their pronunciation experiments. Hines et al. presented participants with masked picture primes and then asked them to pronounce a visual target word presented approximately $600 \mathrm{msec}$ later. This target word was related semantically, associatively, or both semantically and associatively to the prime. However, two aspects of their experiment are particularly unusual. First, Hines et al. presented each prime at least 12 times and each target word at least twice. Although Hines et al. gave their participants a prime-detection posttest and suggested that the primes were unavailable to conscious awareness, it is possible that following a masked picture with a related prime leads to a retrospective-priming process in which the presentation of the target reactivates the prime, allowing conscious identification (see Durante \& Hirshman, 1994; Kahan, 2000). Furthermore, the repeti- tion of both primes and targets could lead to the kind of intraexperimental association learning that may lead to priming based solely on episodic retrieval strategies.

Williams (1996) also found significant priming from categorically related items by presenting participants with visually degraded target items. If the target was only mildly degraded, Williams reported a nonsignificant 5-msec priming effect. However, if the target was severely degraded, Williams reported a significant 47msec effect. Williams suggested that this occurs because visually degrading the target slows down participants' overall reaction time. However, when a target is severely visually degraded, it is likely that participants consciously utilize the prime in order to disambiguate the target from other possible responses (Whittlesea \& Jacoby, 1990). In this case, Williams's results would hardly constitute evidence of automatic priming. Finally, Williams's use of moderate associates undermines the claim that any priming obtained, whether strategic or automatic, was due strictly to feature overlap rather than to association strength.

\section{Perceptually Similar Items}

Schreuder, Flores d'Arcais, and Glazenborg (1984), Flores d'Arcais, Schreuder, and Glazenborg (1985), and Pecher, Zeelenberg, and Raaijmakers (1998) examined priming for items that were either conceptually similar (e.g., torch-candle), perceptually similar (e.g., carrotpaintbrush), or both (e.g., pencil-pen). ${ }^{12}$ Because words like carrot and paintbrush are similar only in their perceptual features, any automatic priming from them must be due to their feature overlap. The results from these three studies are listed in Table 5 and are grouped according to the type of task used (standard LDT and standard pronunciation) and whether the experiment used an $\mathrm{RP}$ of .75 or .30. (None of the stimuli in any of these experiments were associated according to the Nelson et al., 1999, norms.)

As can be seen in Table 5, priming from perceptually similar items in both LDTs and pronunciation tasks depends critically on the RP. For instance, in the standard LDT, the mean perceptual priming of $20 \mathrm{msec}$ is reduced to $4 \mathrm{msec}$ when the RP is lowered from .75 to .30 . Such a pattern suggests that priming for these items is due strictly to conscious strategies. Moreover, Pecher et al. (1998) recently criticized both Schreuder et al. (1984) and Flores d'Arcais et al. (1985) for (1) selecting different items for their unrelated baselines, (2) repeating some prime words in one condition as targets in another, (3) repeating each target item four times, (4) using an SOA of $400 \mathrm{msec}$, and (5) keeping the prime word on the screen while participants responded to the target. In the case of the first criticism, Pecher et al. argued that any obtained priming may simply reflect item differences between their related and unrelated primes. The second and third criticisms reflect possible within-experimentepisodic priming due to participants' learning an association be- 
Table 5

Priming Effects on Reaction Time (in Milliseconds) for Different Types of Perceptually Related Items Sharing a Strong (>.2), a Weak (>.01), or No (<.01) Association According to the Nelson et al. (1999) Association Norms

\begin{tabular}{|c|c|c|c|c|c|}
\hline \multirow[b]{2}{*}{ Task } & \multirow[b]{2}{*}{ Items } & \multirow[b]{2}{*}{ Experimenters } & \multicolumn{3}{|c|}{ Strength of Association } \\
\hline & & & Strong & Weak & None \\
\hline \multirow[t]{7}{*}{ Standard LDT } & $\mathrm{RP}=.75$ & Schreuder et al. $(1984$, Exp. 1)a & - & - & $13^{\dagger}$ \\
\hline & & Flores d'Arcais et al. $(1985, \text { Exp. } 1)^{\mathrm{b}, \mathrm{c}}$ & - & - & $26^{\dagger}$ \\
\hline & & Mean & - & - & 20 \\
\hline & $\mathrm{RP}=.30$ & Pecher et al. (1998, Exp. 1) & - & - & 0 \\
\hline & & Pecher et al. (1998, Exp. 3) & - & - & -5 \\
\hline & & Pecher et al. $(1998, \text { Exp. } 6)^{d}$ & - & - & $16^{*}$ \\
\hline & & Mean & - & - & 4 \\
\hline \multirow[t]{5}{*}{ Standard pronunciation } & $\mathrm{RP}=.75$ & Schreuder et al. (1984, Exp. 1) $)^{\mathrm{a}, \mathrm{b}}$ & & & $28^{\dagger}$ \\
\hline & $\mathrm{RP}=.30$ & Pecher et al. (1998, Exp. 2) & & - & 1 \\
\hline & & Pecher et al. (1998, Exp. 4) d & & - & $9 *$ \\
\hline & & Pecher et al. (1998, Exp. 5)e & & - & 1 \\
\hline & & Mean & & - & 4 \\
\hline
\end{tabular}

Note-All priming effects were computed relative to an unrelated baseline. All SOAs $>350 \mathrm{msec}$. RP, relatedness proportion. $* p<.05$. Contrast not tested or not given. aTargets were repeated four times each. bPrimes remained on the screen during presentation of the target. cParticipants were given a response deadline of $650 \mathrm{msec}$. dParticipants were first given a perceptual study task. eParticipants were first given a read-aloud study task.

tween the items during the initial study phase of the experiment. Finally, the fourth and fifth criticisms suggest that the procedures led participants to notice and strategically utilize prime-target relatedness in the experiments.

Pecher et al. (1998) conducted six experiments designed to systematically test for perceptual priming while correcting some of the methodological problems in the experiments by Schreuder et al. (1984) and Flores d'Arcais et al. (1985). In their first two experiments, Pecher et al. used standard LDT and pronunciation tasks and found null effects of 0 and $1 \mathrm{msec}$, respectively, from their perceptual items. However, in their third and fourth experiments, Pecher et al. first gave their participants study tasks in which they were presented with each item and asked to decide if it referred to a long object, and were then presented with each item again and asked if it referred to a flat object. Although they once again found a nonsignificant $-5 \mathrm{msec}$ of priming in lexical decision (Experiment 3), they obtained a significant $9 \mathrm{msec}$ of perceptual priming in pronunciation (Experiment 4). Furthermore, Pecher et al. questioned whether including associatively related pairs in their experiments may have encouraged backward checking, which would obscure any priming. When these items were eliminated (Experiment 6), Pecher et al. obtained a significant $16 \mathrm{msec}$ of perceptual priming in lexical decision. Pecher et al. therefore concluded that automatic priming does occur for perceptually related items. However, this priming will be seen only if the relevant perceptual features are highly accessible due to recent activation during a previous study task.

Although Pecher et al. (1998) presented a convincing argument for the absence of perceptual priming using standard procedures, one may question their claim that their priming following perceptual study tasks was truly automatic. Their early perceptual task could have caused participants to notice the perceptual similarity of the items and associate each item with the same response (e.g., "flat," "round," "long," or "short"). Therefore, one cannot be certain whether their obtained priming was due to automatic activation of perceptual features or, instead, to participants' conscious identification of the salient perceptual feature during the later priming task. The question of import for our present purposes is whether there is priming from perceptually similar items under normal circumstances, not whether one can produce priming from such items when people are trained to focus selectively on perceptual properties.

Rather than examining whether words for objects with similar perceptual properties (e.g., salt-snow) will produce priming, Lucas (2001) examined priming from the word to the property itself (e.g., salt-white). Along with the perceptual properties, she included essential properties, defined as properties deemed essential to the definition of the concept (e.g., salt-sodium). Lucas (2001) used an LDT in which a visual prime remained on the screen for $500 \mathrm{msec}$. Either immediately (Experiment 1A) or $200 \mathrm{msec}$ (Experiment 1B) after the offset of the prime, a visual target would appear. Lucas (2001) found significant priming for both perceptual $(14 \mathrm{msec})$ and essential (21 msec) properties following a $200-\mathrm{msec}$ ISI (Experiment 1B), yet no priming for either property following a 0-msec ISI (Experiment 1A). However, this study does not demonstrate strong evidence of featurebased priming, for two reasons. First, although these items produced priming in Experiment $1 \mathrm{~B}$ when LDT was used, they failed to produce any priming in later pronunciation experiments (Experiments $2 \mathrm{~A}$ and 2B). Second, the perceptual and essential stimuli that Lucas (2001) used were both moderately associated according to the Nelson et al. (1999) norms (forward associations of .10 and .02 and backward associations of .04 and .14 for the perceptual and essential pairs, respectively). 
Table 6

Priming Effects on Reaction Time (in Milliseconds) for Different Types of Functionally Related Items Sharing a Strong (>.2), a Weak $(>.01)$, or No (<.01) Association According to the Nelson et al. (1999) Association Norms

\begin{tabular}{|c|c|c|c|c|c|}
\hline \multirow[b]{2}{*}{ Items } & \multirow[b]{2}{*}{ Task } & \multirow[b]{2}{*}{ Experimenters } & \multicolumn{3}{|c|}{ Strength of Association } \\
\hline & & & Strong & Weak & None \\
\hline \multirow[t]{5}{*}{ Same } & Standard LDT & Schreuder et al. (1984, Exp. 1)a & - & - & $24^{\dagger}$ \\
\hline & & Flores d'Arcais et al. $(1985, \text { Exp. 1) })^{\mathrm{b}, \mathrm{c}}$ & - & - & $16^{\dagger}$ \\
\hline & Standard pronunciation & Schreuder et al. (1984, Exp. 2) $)^{\mathrm{b}, \mathrm{c}}$ & - & - & $10^{\dagger}$ \\
\hline & Standard pronunciation with degraded target & Flores d'Arcais et al. $\left(1985\right.$, Exp. 1) ${ }^{\mathrm{b}}$ & - & - & $25^{\dagger}$ \\
\hline & & Mean & - & - & 19 \\
\hline Script & Continuous LDT & Moss et al. (1995, Exp. 3) & -7 & -17 & - \\
\hline Instrument & Continuous LDT & Moss et al. (1995, Exp. 3) & $30 *$ & - & $26^{*}$ \\
\hline \multirow[t]{4}{*}{ Mixed list } & Standard LDT & Seidenberg et al. (1984, Exp. 4) & $31 *$ & - & $32 *$ \\
\hline & Two-item LDT & Fischler (1977) & - & - & $84 *$ \\
\hline & Standard pronunciation & Seidenberg et al. (1984, Exp. 4) & - & - & $9 *$ \\
\hline & & Mean & 31 & - & 42 \\
\hline
\end{tabular}

Note-All priming effects were computed relative to an unrelated baseline. All SOAs $>350$ msec. Same, items with the same function; script, functionally related "script" items; instrument, functionally related "instrument" items; mixed, undifferentiated functional items. $* p<.05$. Contrast not tested or not given. aTargets were repeated four times each. bPrimes remained on the screen during presentation of the target. 'Participants were given a response deadline of $650 \mathrm{msec}$.

\section{Functional Relations}

Moss et al. (1995) proposed that many items traditionally treated as associated actually hold functional relations that are a core part of the items' semantic representations. In particular, Moss et al. (1995) identified two types of functionally related items: instruments and scripts. Instruments (e.g., hammer-nail) are related in that the intended function of one of the items is to perform some action on the other. Script relations (e.g., restaurant-wine) involve items that are part of the same script or schema (see Rumelhart, Smolensky, McClelland, \& Hinton, 1986; Schank \& Abelson, 1977). Because most people's schema of a restaurant includes items such as wine, these items can be said to be related at the level of meaning. In addition, some researchers have classified items such as torch and candle as functionally related, since they share the same primary function (i.e., to provide light). In early experiments, Fischler (1977) and Seidenberg et al. (1984), who claimed to find significant, automatic, "semantic-only" priming, actually utilized a mixture of all three of these types of functional relations in their stimuli.

In Table 6, the results from six experiments testing priming from functionally related items are presented. As in Tables $2-5$, in Table 6 the experiments are grouped by the type of task used (standard LDT, standard pronunciation, pronunciation with a visually degraded target, continuous LDT, and two-item LDT). In addition, these studies are organized according to the type of functional relation (same function, script relation, instrument relation, and mixed list). Once again, priming is reported under the column representing the association strength of the stimuli.

Priming from items sharing the same function (e.g., torch-candle) has been examined directly in only two experiments. Both Schreuder et al. (1984) and Flores d'Arcais et al. (1985) included functionally similar items (along with the perceptually related items discussed earlier) in their lexical decision and pronunciation experiments. Schreuder et al. found a significant effect of functional similarity in an LDT (Experiment 1) but no significant effect in a pronunciation task (Experiment 2). Flores d'Arcais et al., however, found the opposite pattern when using a response deadline LDT and a visually degraded target in a pronunciation task. (This pattern of results is opposite to that reported earlier for perceptually related items.) However, because only two experiments have been reported and, as was discussed previously, both suffer from methodological limitations, more research is needed before any conclusions can be drawn concerning priming from these items.

Moss et al. (1995) examined priming for both script relations (e.g., restaurant-waiter) and instrument relations (e.g., hammer-nail) using strongly associated or nonassociated (actually, weakly associated) prime-target pairs. ${ }^{13}$ Although Moss et al. (1995) found priming for both instruments and scripts in their first two experiments, in which primes were presented auditorily, they found no priming from either strongly or weakly associated script items in their third experiment, in which they used visual presentation and a continuous LDT. However, unlike their script items, both their strongly associated and nonassociated instrument items continued to show significant priming, even under the latter conditions. On the basis of this pattern of results, Moss et al. (1995) concluded that automatic priming does occur for instrument items, even in the absence of association.

In the bottom of Table 6 , the results of two studies on priming from mixed functionally related semantic pairs are presented. Fischler (1977) used Meyer and Schvaneveldt's (1971) two-word LDT and found a large 84msec priming effect. He concluded that semantic facilitation can occur purely on the basis of shared overlap in 
Table 7

Priming Effects on Reaction Time (in Milliseconds) for Synonym and Antonym Pairs Sharing a Strong ( $>.2)$, a Moderate ( $>$.10), or a Weak (>.01) Association According to the Nelson et al. (1999) Association Norms

\begin{tabular}{|c|c|c|c|c|c|c|c|c|}
\hline \multirow[b]{3}{*}{ Task } & \multirow[b]{3}{*}{$\mathrm{RP}$} & \multirow[b]{3}{*}{ Experimenters } & \multicolumn{6}{|c|}{ Strength of Association } \\
\hline & & & \multicolumn{2}{|c|}{ Strong } & \multicolumn{2}{|c|}{ Moderate } & \multicolumn{2}{|c|}{ Weak } \\
\hline & & & Syn & Ant & Syn & Ant & Syn & Ant \\
\hline \multirow{5}{*}{ Standard LDT } & $\mathrm{RP}=.92$ & McKoon \& Ratcliff (1995, Exp. 2)b & $21^{\dagger}$ & $44^{\dagger}$ & - & - & - & - \\
\hline & & McKoon \& Ratcliff (1995, Exp. 2)c & $54 \dagger$ & $2^{\dagger}$ & - & - & - & - \\
\hline & & Mean & 38 & 23 & - & - & - & - \\
\hline & $\mathrm{RP}=.50$ & Hodgson $\left(1991\right.$, Exp. 1A) ${ }^{a}$ & $16^{\dagger}$ & $14^{\dagger}$ & - & - & - & - \\
\hline & & Perea \& Gotor (1996, Exp. 3) & - & - & - & - & $17 *$ & - \\
\hline \multirow[t]{2}{*}{ Masked LDT } & $\mathrm{RP}=.50$ & Perea \& Rosa (2002, Exp. 1) & $17 *$ & $30 *$ & - & - & - & - \\
\hline & & Perea \& Rosa (2002, Exp. 2) & - & - & $21 *$ & - & - & $14 *$ \\
\hline \multirow[t]{5}{*}{ Standard pronunciation } & $\mathrm{RP}=.92$ & McKoon \& Ratcliff (1995, Exp. 4)b & $-1 \dagger$ & $7^{\dagger}$ & - & - & - & - \\
\hline & & McKoon \& Ratcliff (1995), Exp. 4)c & $9 \dagger$ & $12^{\dagger}$ & - & - & - & - \\
\hline & & Mean & 4 & 10 & - & - & - & - \\
\hline & $\mathrm{RP}=.50$ & Hodgson $(1991$, Exp. 3)a & $7^{\dagger}$ & $1^{\dagger}$ & - & - & - & - \\
\hline & & Perea \& Gotor (1996, Exp. 4) & - & - & - & - & $10 *$ & - \\
\hline
\end{tabular}

Note-All priming effects were computed relative to an unrelated baseline. Standard LDT, single target preceded by prime word; RP, relatedness proportion. * $*<<.05$. Contrast not tested. aParticipants responded to same items over four SOA conditions. bItems presented in "antonym" list context. cItems presented in "synonym" list context.

features between a prime and a target. Seidenberg et al. (1984, Experiment 4) later provided some support for Fischler's results by finding reduced, yet still significant, priming effects of $32 \mathrm{msec}$ in a standard LDT and of $9 \mathrm{msec}$ in a pronunciation task. These results lend further support to the existence of automatic priming for functionally related items.

\section{Synonyms and Antonyms}

Interestingly, although antonyms and synonyms combined comprise about $40 \%$ of responses in association norms (see Table 1), few have examined priming from these items specifically (Hodgson, 1991; McKoon \& Ratcliff, 1995; Perea \& Gotor, 1996; Perea \& Rosa, 2002). In Table 7 , the results from these experiments are broken down by the type of task used (standard LDT, masked LDT, and standard pronunciation) and RP (either .50 or .92$)$.

Hodgson (1991) included synonyms and antonyms (as well as the other types of prime-target relations discussed previously) in both LDTs and pronunciation tasks. Averaged across SOA, Hodgson found overall priming effects of 16 and $14 \mathrm{msec}$ for his synonyms and antonyms, respectively. In his pronunciation task (Experiment 3), these effects dropped to 7 and $1 \mathrm{msec}$, respectively. However, because each prime and each target was repeated four times to each participant across sessions with a different prime-target pairing each time, and no attempt was made to examine the individual priming effects, conclusions based on this study alone would be premature.

McKoon and Ratcliff (1995) presented participants with both synonyms and antonyms in an experiment in which they examined the effects of list context on priming. McKoon and Ratcliff's (1995) stimuli consisted of both a synonym prime and an antonym prime for each target (e.g., close, far, near). List context was manipu- lated by presenting these synonym and antonym pairs among other filler pairs that were mostly synonyms or antonyms. Using the standard LDT, McKoon and Ratcliff (1995) found overall priming of 38 and $23 \mathrm{msec}$ for synonyms and antonyms, respectively. However, these effects were dependent on the fact that there was a majority of matching relations in the list. (Unfortunately, because McKoon \& Ratcliff, 1995, were primarily interested in the effects of list context per se, the individual priming effects were not tested for significance.) McKoon and Ratcliff (1995) argued that such list context effects are strong evidence against spreading activation, since the same amount of activation should spread to related items regardless of the particular list structure. However, because McKoon and Ratcliff (1995) used the standard LDT, a .92 RP, and a .875 NWR, their list context effects may be due entirely to the participants' use of strategic processes such as expectancy generation or backward checking.

In their fourth experiment, McKoon and Ratcliff (1995) reduced backward checking by using only word targets in a pronunciation task. Although they replicated the overall list context effect, the pattern of priming across the synonym and antonym pairs was less pronounced. As was mentioned previously, it is difficult to draw any firm conclusions from this study. Although the effects of backward checking were minimized, their pronunciation experiment still utilized a 250 -msec SOA and a .92 RP, making expectancy generation likely and therefore clouding the interpretation of these results (see Keefe \& Neely, 1990, for a discussion of the influence of conscious expectancies in pronunciation).

Perea and Gotor (1996) and Perea and Rosa (2002) made additional attempts to examine priming for synonyms. Perea and Gotor found priming for their synonym pairs in both an LDT (17 msec) and a pronunciation task 
(10 msec). Because the SOA was only $69 \mathrm{msec}$ and they found significant priming across tasks, it seems likely that this effect is the result of automatic processes. Perea and Rosa later found priming for both synonyms and antonyms (presented alongside the category coordinate pairs discussed previously) in a masked priming LDT with items presented for between 66 and $166 \mathrm{msec}$. This priming occurred for both their strongly associated items (Experiment 1) and their weakly associated items (Experiment 2). Unfortunately, as was mentioned previously, these items were taken from Spanish norms, making comparisons with forward and backward associations in the Nelson et al. (1999) norms difficult. However, the translations provided in both studies do appear to have stronger associations in the backward direction (.09 and .17 for the synonyms used by Perea \& Gotor, 1996, and those used by Perea \& Rosa, 2002, respectively) than in the forward direction (.06 for both the synonyms used by Perea \& Gotor, 1996, and those used by Perea \& Rosa, 2002), suggesting that backward checking could potentially play a role.

The significant priming for synonyms and antonyms obtained by Perea and Gotor (1996) and Perea and Rosa (2002) converges with the numerical priming of Hodgson (1991) and McKoon and Ratcliff (1995), suggesting that synonym and antonym pairs indeed produce small priming effects. Clearly, however, more experiments are needed to test the automaticity of priming from both synonym and antonym relations before any strong conclusions can be drawn.

\section{Auditory Priming Studies}

Several experimenters looking for "pure" semantic priming presented the primes and, in some cases, the targets auditorily to participants. As Ostrin and Tyler (1993) argued, "[because] most of the studies on automatic semantic priming have used visually presented material, [one] cannot simply assume that the type of priming that exists in the visual modality also characterizes auditorily presented primes and targets" (p. 149). Nonetheless, such studies are potentially important and useful in providing insight into the mechanisms of semantic priming without association. For this reason, in the present section six auditory studies designed to test priming without association are briefly examined. These studies are shown in Table 8, divided according to the presentation modality of the target (visual or auditory) and the type of task used (standard or continuous LDT).

Zwitserlood and Schriefers (1995), Moss, McCormick, and Tyler (1997), and Tyler, Moss, Galpin, and Voice (2002) have all examined semantic priming without association using auditory primes and visual targets. Using semantically related Dutch pairs that supposedly do not share an association, Zwitserlood and Schriefers presented participants with auditory vocal onsets (e.g., "cap") compatible with approximately 4 words (e.g., captain, capital, captive, capsize). Visual targets were presented for a lexical decision response immediately following the

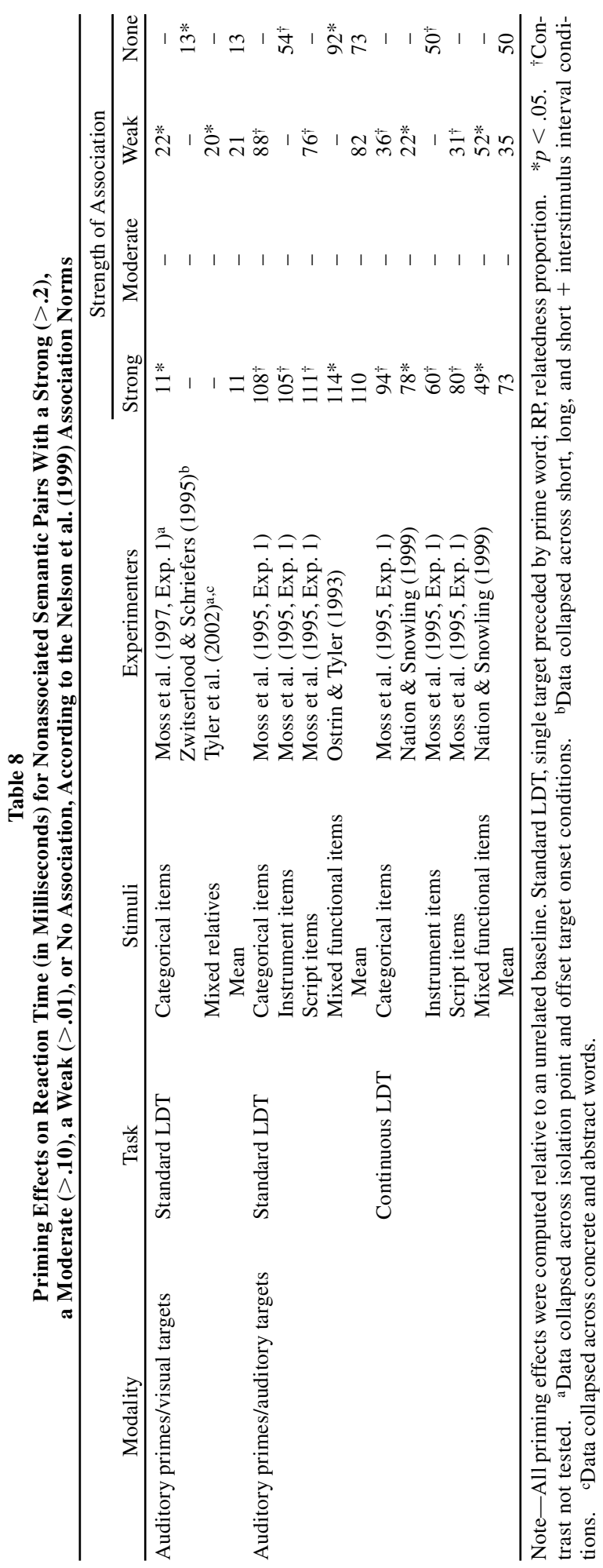


offset of the fragment. In another condition, they presented even shorter, more ambiguous fragments compatible with around 13 words, and visual targets were presented either immediately or $200 \mathrm{msec}$ after the offset of the fragment. Overall, they found a significant $13 \mathrm{msec}$ of priming. However, closer inspection revealed that this effect came exclusively from their long-onset $(19 \mathrm{msec})$ and short-onset +200 -msec-delay conditions $(21 \mathrm{msec})$, rather than from the short-onset-only condition $(0 \mathrm{msec})$. Zwitserlood and Schriefers concluded that (1) auditory primes activate multiple words candidates, (2) these candidates activate related words that share semantic features, and (3) this activation takes time to accrue. Tyler et al. provided additional support for this claim, finding an overall 20 -msec priming effect from weakly associated visual targets presented immediately after the offset of the prime, following a 250-msec delay, or immediately after enough information in the prime had been provided to allow the participant to correctly guess its identity (the so-called isolation point). Moreover, using a similar paradigm, Moss et al. (1997) found at least as much priming from their weakly associated items as from their strongly associated items, regardless of whether the primes were provided in their entirety or only up to their isolation points.

Using both auditory primes and auditory targets, Ostrin and Tyler (1993), Moss et al. (1995), and Nation and Snowling (1999) found significant priming for semantic pairs supposedly lacking an association. As was mentioned previously, Moss et al. (1995) examined priming for multiple types of both strongly and very weakly associated relations, including items belonging to the same script, items with an instrumental relation, and items with categorical relations. In their first experiment using a standard LDT, Moss et al. (1995) appeared to obtain priming for all types of semantic relations, even when the pairs shared little to no associative relation (the individual effects were not tested). This pattern of priming for both strongly (114 msec) and weakly (92 msec) associated stimuli was also found by Ostrin and Tyler using items taken from Fischler (1977). In their second experiment, Moss et al. (1995) used a continuous LDT procedure and found the same pattern. Moreover, using this same continuous procedure, Nation and Snowling found, for their categorical pairs, a significant priming effect of $22 \mathrm{msec}$, which was boosted to $78 \mathrm{msec}$ for associated pairs. However, for their functional items, no such associative boost exists (priming of $49 \mathrm{msec}$ and $52 \mathrm{msec}$ for associated and nonassociated functional pairs, respectively). Whether such an associative boost depends on the use of categorical items is currently unknown and would be of much interest.

However, the extent to which auditory priming reflects backward checking is still unknown. Since an echoic trace of an auditory prime should still be present throughout the presentation of a visual or auditory target, the target item could be integrated with the prime. Any strategic or accidental integration of the target with the echoic trace of the prime could lead to a relatedness-based decision. Moreover, this should occur in both standard and
continuousLDTs. It is therefore still unclear whether the auditory priming occurs before or after lexical retrieval of the target. Indeed, there is some empirical support for backward priming in these tasks. Using their crossmodal paradigm discussed previously, Moss et al. (1997, Experiment 2) found a marginal $10 \mathrm{msec}$ of priming $(p=.09)$ for backward associates, which clearly would not have differed from some of their "pure-semantic" effects of 9,11 , and $13 \mathrm{msec}$ reported in their first two studies. Tyler et al. (2002) also found a marginally significant correlation $(r=.212, p=.06)$ between priming effects and backward associative strength in their experiment.

\section{Summary of "Pure Semantic" Priming}

In explaining the conflicting patterns of priming across experiments, Moss et al. (1995) and McRae and Boisvert (1998) identified the importance of specifying what one means by a "semantic" relation. Whereas category coordinate pairs were used in the experiments in which null effects were claimed, experiments that obtained pure semantic priming have tended to make use of items sharing much overlap in features. In agreement with this logic, I have examined the evidence of automatic priming for each type of semantic relation separately. Although in many cases the results are ambiguous, there are clearly distinct patterns across different types of relations. It would therefore be foolish to aggregate all these effects under one "pure semantic" heading.

As was noted earlier, the overall evidence of priming from category coordinates is weak. Across studies, approximately $31 \mathrm{msec}$ of priming from these items is found using the standard LDT. However, this task is subject to conscious strategies, and in some of these studies moderately to strongly associated items were used. By contrast, only 4 msec of priming from these items occurs in the pronunciation task. Although priming does appear to occur for category members in the degraded pronunciation task, this task was criticized for encouraging the deliberate use of primes to disambiguate targets. Overall, the evidence of category coordinate priming is weak and likely reflects task-dependent strategic processes such as expectancy generation and semantic matching.

The evidence for automatic perceptually based priming is at least as weak as that for coordinates. Although early experiments by Schreuder et al. (1984) and Flores d'Arcais et al. (1985) appeared to provide evidence of such effects, these experiments have been criticized for methodological problems that should encourage strategic processing. After correcting these problems, Pecher et al. (1998) consistently failed to find perceptual priming in either LDTs or pronunciation tasks unless participants were first given practice categorizing the primes and targets in a perceptual task. However, such practice likely leads to the formation of episodic associations between the items.

More convincing evidence has been reported for functionally related items. Of most importance, Moss et al. (1995) found priming for instrument-related items with no association using a continuous LDT. Thus, priming 
from these items does not appear to require strategic processing and is not due to an association between the stimuli. Also, these items appear most similar to those originally used by Fischler (1977) and Seidenberg et al. (1984), both of whom found significant priming. However, the results for script-related items (e.g., restaurantwine) and items sharing the same function (e.g., torchcandle) are not as convincing. For script-related items, priming for visually presented items in the continuous LDT was nonsignificant for both associated and nonassociated pairs. Both Schreuder et al. (1984) and Flores d'Arcais et al. (1985) included pairs sharing the same function in their experiments. However, because of problems with both of these experiments, no conclusions regarding priming from these items can be offered at this time.

Only a few researchers have explicitly examined priming from synonyms and antonyms. Hodgson (1991) appeared to find a small amount of priming from both synonyms and antonyms in the LDT; however these effects were not tested for significance. These numerical priming effects were absent in a pronunciation task. McKoon and Ratcliff (1995) also provided data supportive of a strategy-dependent interpretation of priming from these synonyms and antonyms. However, as in the work of Hodgson, these effects are severely clouded by methodological problems that encourage strategic processing. Also, Perea and Gotor (1996) found significant priming for synonyms in both the standard LDT and pronunciation tasks, suggesting that this effect is indeed automatic. Perea and Rosa (2002) later found significant masked priming for both synonyms and antonyms. Because Perea and Gotor (1996) and Perea and Rosa (2002) claimed that their items were not associated, this experiment provides perhaps the strongest evidence of automatic priming for synonyms and antonyms. Clearly, more experiments similar to those of Perea and Gotor (1996) and Perea and Rosa (2002) are needed to test priming for both antonyms and synonyms before any strong conclusions can be drawn.

Finally, experimenters who have used auditory primes and either auditory or visual targets in their experiments have consistently found priming for items sharing little to no associative relation. This has been found using both the standard LDTs and continuous LDTs. However, as was suggested earlier, comparisons with visually presented studies is unwarranted, because an echoic trace of the prime should be available (in both tasks) during the presentation and encoding of the target. Nonetheless, the finding of such agreement across experiments is certainly suggestive of automatic feature-based priming for pairs presented in this modality.

\section{COMPARISON WITH LUCAS (2000)}

Although the present investigation has taken a much more microanalytic approach, many of the same conclusions have been reached as in Lucas (2000). As did Lucas
(2000), the present review suggests that automatic priming does occur for functionally related items (at least instrument relations). Also, in consistency with Lucas (2000), there appears to be an associative boost (when items are presented in the visual modality) such that semantic pairs sharing an association show larger priming than nonassociated pairs. However, one cannot tell, on the basis of the available evidence, whether this associative boost is due to combined lexical and semantic connections, as Collins and Loftus (1975) predicted, or simply to a greater overlap in semantic features between these items (Chiarello et al., 1990; Lucas, 2000; McRae \& Boisvert, 1998).

There are three critical points, however, on which the present conclusions differ from those of Lucas (2000). First, although Lucas (2000) claims that automatic priming does occur for category coordinates, close inspection of her studies reveals that priming from these items is not automatic. The significant effect size reported by Lucas (2000) most likely results from her inclusion of studies with actually moderate to strong association strengths and methodologies that encourage strategic processing. When these factors are controlled, priming from these items is eliminated. A second difference concerns her conclusion of an overall pure semantic effect. As I have argued, collapsing across different relation types in this manner can lead to drastically misleading conclusions. Finally, whereas Lucas (2000) concluded that there is little to no evidence of pure associative priming, the present review leads to the opposite conclusion. (Lucas, 2000, did not address mediated priming in her analysis.) Whereas more experiments are undoubtedly needed to verify priming for collocates and episodic relatives, the results are quite strong and convincing for mediated items. For these items, priming reliably occurs under conditions that have been shown to prohibit strategic processing. In fact, mediated priming is strongest when strategic processing is minimized and disappears when strategic processing is encouraged. This dissociation of mediated priming from strategic priming provides strong evidence that mediated priming is automatic. Thus, contrary to the conclusions of Lucas (2000), the converging results obtained across mediated priming studies supports the existence of pure associative priming.

\section{POTENTIAL LIMITATIONS AND ISSUES}

There are two aspects of the present review that drastically differ from those of Lucas (2000). First, to avoid a publication bias, Lucas (2000) included both published and unpublished studies, whereas the present review includes only peer-reviewed and published studies. Second, Lucas (2000) collapsed across studies in which visual and auditory presentation of primes was used to obtain her measures of semantic priming, whereas in the present review I examine priming from these two modalities separately. Each of these issues is discussed below. 


\section{Published Versus Unpublished Studies}

As was mentioned previously, Lucas (2000) included both published and unpublished studies, whereas the present review includes only published studies. In the present case, it is unclear whether this should increase or decrease one's estimates of effect size. In one sense, including unpublished studies reduces the publication bias problem that results from significant results being published whereas null effects are relinquished to some file drawer (Rosenthal \& DiMatteo, 2001). On the other hand, these studies could contain serious methodological flaws that lead to inflated estimates of priming. An informal examination of the effect sizes appears to favor the first explanation, since the unweighted mean effect size from published studies was .35 , an estimate almost twice as large as the .18 effect size from unpublished studies. Of importance, even in the face of an apparent publication bias that should inflate pure semantic priming estimates, very little evidence of such priming was found in the present review.

\section{Auditory Versus Visual Presentation}

Although Lucas (2000) did not analyze the effect of presentation modality, the auditory studies appear to have contributed greatly to her effect size estimates. In fact, if one simply averages her unweighted effect sizes from the five studies in which auditory presentation was used, the resulting Cohen's $d$ of .51 is more than twice as large as the $d$ of .25 obtained from the remaining visual presentation studies. In addition, although no current support was found for categorical priming on the basis of studies in which visual presentation was used, such priming did occur in studies in which the stimuli were presented auditorily.

It is unclear why presentation modality should make such a large difference in effect size estimates. One possibility is that auditory primes have a preferred access to their semantic representations, similar to the direct route to semantics attributed to pictorial stimuli (see Chiarello, 1998, for a discussion). Alternatively, because auditory primes leave a longer echoic trace that persists after the presentation of the target, an equally plausible explanation is that such a trace allows for some type of strategic matching or prime-target integration by participants. In fact, Balota, Watson, Duchek, and Ferraro (1999) have argued that such as integration of auditory primes with visual targets occurs not only in LDT, but in pronunciation tasks as well. This modality effect in pure semantic priming could potentially be a fruitful area for future studies. More research is needed to differentiate between these two possible accounts.

\section{THE SEARCH FOR "PURITY" IN EXPERIMENTAL STIMULI}

As was mentioned previously, the most common method for demonstrating either association-based or feature-based priming is the use of "pure associative" or "pure semantic" pairs. I have already discussed the dif- ficulty in demonstrating null semantic similarity from associates taken from norms. In particular, every type of association listed in Table 1 reveals a featural relation. However, similar arguments apply to attempts to demonstrate null association through selection of "pure semantic" pairs. In particular, there are three essential problems with the assumption of null association. Of most importance, simply because a word is not given as a first response to a cue does not mean that it lacks an association. The concept of spreading activation strongly implies that more than one target should be activated by a given prime. For instance, the pairs cycle-system and weep-sad have an association strength of $2 \%$ according to the Nelson et al. (1999) norms. Does this mean they are equally unassociated? Certainly not. In fact, sad is the 2 nd highest response (out of 3 ) to weep, whereas system is the 8th highest response (out of 17) to cycle. The fact that $92 \%$ of participants respond "cry" when given weep doesn't leave much room for the response "sad." As a result, one could compare first associates with low associates and show an effect of association strength, but one cannot use the absence of association strength (or use a weak association), given traditional norms, to infer an absence of association. To do this, one would need a procedure whereby a large number of participants list numerous responses to each cue. A second problem concerns the possibility of mediated priming for "nonassociated" items. As Shelton and Martin (1992) suggested, nonassociated category coordinates (e.g., chicken-duck or wasp-fly) could activate each other via a mediated category node (e.g., BIRD or INSECT, respectively). Other words (e.g., clock or light) could also serve as mediators for pairs such as watch-alarm or match-lighter, respectively. The third problem with many "pure semantic" studies is that backward relations could exist between the stimuli. Using the standard LDT, such backward relations are especially likely to contribute to priming. Many items that likely contain a strong backward association are not listed, because the targets are of such low frequency that they are not usually given as cues in association norms and, therefore, have no record (e.g., pitchercarafe). This is an especially likely problem in "pure semantic" studies, since the targets are usually lower in frequency. To summarize the main point of these concerns, any "pure semantic" priming may be (at least partially) due to associations between the stimuli.

\section{CONCLUSIONS AND IMPLICATIONS FOR MODELS OF SEMANTIC PRIMING}

This article has provided an in-depth look at the debate between association strength and feature overlap as the basis for semantic priming. On the basis of the preceding sections, the following conclusions can be drawn, each with important implications for current models of semantic priming: (1) Through experiments on mediated priming, strong evidence of automatic priming based purely on association has been found; (2) automatic pure 
semantic priming most likely occurs for items sharing a functional instrument relation; (3) automatic priming most likely occurs between synonym and antonym pairs; (4) no automatic priming occurs for nonassociated category coordinates or perceptual relatives; (5) priming occurs for all types of semantic relations when presented in the auditory modality, although the locus and automaticity of such priming is still in question; and (6) the status of many relations, such as phrasal associates, episodic relatives, script relations, and items with similar functions, is currently unclear and requires further experimentation that tightly controls for strategic processing.

In terms of models of semantic priming, the most important conclusion is that automatic priming appears to be due to both association strength and feature overlap. Thus, these results are consistent with claims of both associative and semantic contributions to priming (Balota, 1990; Balota \& Paul, 1996; Chiarello et al., 1990; Fodor, 1983; Moss et al., 1994; Moss et al. 1995; Tanenhaus \& Lucas, 1987; Williams, 1996). The results are less clear, however, concerning whether concepts are represented as distinct whole nodes or, instead, as combinations of individual features.

\section{Localist Models}

Following the assumptions laid out by association theories of semantic memory (Anderson, 1983; Collins \& Loftus, 1975), many researchers have assumed that priming takes place by the activation of whole units (i.e., nodes) through connections to other whole units. Although the present discussion focuses on the network model of Collins and Loftus, many models based on this localist assumption exist (Forster, 1979; McClelland \& Rumelhart, 1981; Morton, 1969).

There are two ways in which Collins and Loftus's (1975) spreading activation model could account for the present data. One way is to assume that associative priming can occur intralexically (Fodor, 1983) due to lexical co-occurrence. This explanation accounts for the associative boost to priming. For example, if the node DOG is preceded by the node CAT, activation is presumed to spread at both the conceptual level (due to shared semantic features) and the lexical level (due to a lexical association). The multiple sources of activation should therefore lead to more priming than for items connected only at the conceptual level (e.g., SHEEP-HORSE) or at the lexical level (e.g., help-wanted). This hypothesis also accounts for mediated priming, as activation spreads across multiple nodes in either the lexical or the semantic network.

The second way this model could account for both semantic and associative priming is based on an important distinction between semantic relatedness and semantic distance. According to Collins and Loftus (1975), semantic distance is the "shortest path [direct or indirect] between two nodes" (p. 412, note 3). For example, the direct path between the node FIRE ENGINE and the node HOUSE is very short, indicating that activation does not need to travel far from FIRE ENGINE to reach HOUSE and should happen quickly. However, it is the sum of the strengths of all the connections between FIRE ENGINE and HOUSE that indicates their semantic relatedness. For instance, consider the difference in relatedness between FIRE ENGINE and HOUSE and FIRE ENGINE and CAR. Although both pairs have roughly the same semantic distance in their models, FIRE ENGINE and CAR are much more semantically related because they share numerous indirect pathways through other nodes, such as ROAD, TRUCK, and DRIVE. Although the level of activation for any one path decreases as it spreads out across multiple nodes, the converging activation from multiple path ways leads to much stronger activation of related items.

The problem with this model is closely related to its strength. That is, network models can account for almost any pattern of data by (1) appealing to the notion that activation spreads within and/or between the lexical and conceptual levels, (2) appealing to different tasks by differentially tapping lexical or conceptual levels of representation, or (3) appealing to either bidirectional or asymmetric activation. In addition, this model makes few clear predictions regarding priming for different types of semantic relations. One therefore runs the risk of circularity by waiting for more empirical data before postulating which of these relations has more connections in the lexical and conceptual networks. For instance, this model gives no a priori explanation as to why functional semantic relations (e.g., hammer-nail) should lead to priming whereas other types of semantic relations, such as coordinates (e.g., pig-fox), do not. One could postulate that functional relations share more connections than coordinates, but this explanation again runs the risk of being post hoc.

\section{Distributed Models}

More recent attempts to model semantic priming have focused on distributed rather than local representations (Kawamoto, 1993; Masson, 1995; McClelland \& Rumelhart, 1985; Moss et al., 1994; Plaut \& Booth, 2000; Plaut, McClelland, Seidenberg, \& Patterson, 1996; Seidenberg \& McClelland, 1989; Sharkey \& Sharkey, 1992). Although there are different types of distributed models, the underlying assumption of all of them is that the units of a network are not whole words but simple, highly interconnected features. Learning is defined as changes in the weights of the connections between the features, and the memory of a concept is distributed over many different such features. Currently, the most popular type of distributed network for modeling semantic priming is a recurrent network, in which all the features are interconnected and the model learns by settling into frequently occurring patterns. These learned patterns are referred to as attractor basins, because the network is biased to settle into one of these known patterns when given partial information. Thus, like humans, these models tend to interpret new information in terms of previously learned concepts and meanings. Finally, some of these models 
can retain important information across sequences, allowing the most recent trial to influence how quickly the network settles on the current trial.

These models clearly predict priming from items sharing a overlap in features. If the previous word was semantically similar to the new word, the network will settle faster to the attractor basin of the new stimulus than if the previous word was dissimilar. Some researchers have used a spatial metaphor for describing basins of attraction, claiming that more similar patterns are stored closer together so that the network has a shorter distance to travel (a process referred to as gradient descent) in moving out from the bottom of one basin (i.e., the prime word) and into the new appropriate basin (i.e., the target word). Distance, in this sense, refers to the amount of updates (iterations) the model requires in order to stabilize on the new pattern. On the basis of these models, researchers have argued that feature overlap alone is necessary and sufficient to obtain semantic priming (McRae \& Boisvert, 1998; McRae, De Sa, \& Seidenberg, 1997).

Other researchers have instead capitalized on the fact that recurrent networks can be sensitive to previous trials and used this property to model not only feature-based priming, but associative priming as well (Kawamoto, 1988, 1993; Masson, 1995; Moss et al., 1994; Plaut \& Booth, 2000). For instance, Moss et al. (1994) argued that distributed networks can be constructed to help in the learning of sequences of activation such that the model can settle into the target pattern more quickly following an associated prime than following a nonassociated prime. In addition, Plaut (1995) found that his recurrent network settled faster into the attractor basin of the target when starting from an associated prime than when starting from a nonassociated prime. Thus, these models can be used to model both feature-based and associative-based priming. Using the spatial metaphor, one might suggest that featurally similar primes have attractor basins closer to those of the target in multidimensional space, whereas associative primes influence the tendency of the gradient descent to head toward the basin of the associated target.

As one might expect, these new distributed models can account for many of the same findings as the older localist models. For instance, these models predict automatic priming for featurally related items. Moreover, they can now account for both pure associative priming and the associative boost, because associated items and semantically similar items can influence the network's behavior independently. Accordingly, for the concepts CAT and DOG, not only would the attractor basins be close to each other (meaning that the items share similar patterns), but the transition between the attractor basins would be well learned.

Moreover, distributed models can also predict different patterns of priming for functional, perceptual, and categorical items on the basis of their different locations and processing modules. Because the different types of features would be stored in separate modules, demon- strations of differential impairment of certain categories of semantic knowledge, such as living things versus artifacts, is consistent with these models (Warrington \& McCarthy, 1987; Warrington \& Shallice, 1984; see also Farah \& McClelland, 1991, and Shelton \& Caramazza, 1999 , for further support for distributed representations from patterns of neurological impairment). However, no clear prediction regarding which types should be automatic versus conscious is currently available.

The most serious problem for these models concerns the automatic mediated priming results. Intuitively, one might argue that because LION shares features with TIGER and TIGER shares features with STRIPES, LION can prime STRIPES. However, this assumption requires that the entire concept of TIGER become activated by the presentation of LION, including features not shared by LION. As Masson (1995) argued, this is not how distributed models explain priming. Indeed, the whole point of distributed models is that one doesn't need to postulate entire nodes, but can instead rely simply on shared features. According to Masson, distributed models cannot explain such priming without assuming some degree of semantic similarity between the mediated items (i.e., lion and stripes) themselves. However, this seems unlikely. Inspection of mediated items (e.g., lion-stripes) reveals much less featural similarity than inspection of items such as coordinates (e.g., pig-fox or steel-iron) that do not produce automatic priming. Moreover, Livesay and Burgess (1998) found that mediated items do not cooccur in language any more than their unrelated controls do. In order to explain mediated priming, distributed models would have to claim a spread of activation that occurs between successive patterns of features during training. However, such a drastic modification of the original logic of distributed models would render them indistinguishable from localist network models.

\section{Lexical Co-occurrence and the HAL Model}

Recently, a method of modeling semantic memory based on the global co-occurrence of words in text has emerged (Burgess, 1998; Burgess \& Lund, 1995; Foltz, 1996; Landauer \& Dumais, 1997; Lund \& Burgess, 1996; Spence \& Owens, 1990). Although these approaches have been developed for different purposes, they have in common the assumption that the overall meaning of a word can be extracted by examining the surrounding context in which the word appears across a large range of text. The present discussion will focus on the Hyperspace Analogue to Language (HAL) model developed by Curt Burgess and colleagues, primarily because it is intended as a potential model for how meaning becomes represented in semantic memory.

The HAL model of semantic memory assesses a word's meaning through the construction of a co-occurrence matrix based on a sample of 160 million words taken from Usenet newsgroups. Co-occurrence within a 10 -word window is derived by calculating direction-sensitive strength values for all words that co-occur. For any 2 
words, these values are inversely proportional to the number of other words separating them in the window. This strength value presumably detects the global rather than local co-occurrence of words. For example, the words in a pair such as police-criminals are likely to co-occur many times across a sample (e.g., a global co-occurrence), whereas the pair police-reached (as in the sentence "one of the police reached for his gun") is idiosyncratic to the surface structure of a particular sentence (e.g., a local co-occurrence) and much less likely to co-occur again in other sentences.

In HAL, the meaning of a word becomes represented as a vector of feature elements consisting of other words with which it co-occurs. Thus, a word such as road becomes defined by the words with which it co-occurs, such as sign, path, drive, and car. In this way, the model can capture semantically related concepts, such as ROAD and STREET, that have a high degree of overlap in their vector elements (i.e., other words). Thus, even though the words road and street almost never co-occur in the same sentence, these words are represented by HAL as closely related because they each tend to co-occur with the same other words (defined as a word's context or neighborhood).

Because a word's meaning is represented as a list of vector elements, the HAL model appears more in line with a distributed model of semantic memory than with a localist model. However, in HAL the elements that make up each word's vector are simply other words with which it co-occurs. Therefore, the vector for a word (which supposedly represents its meaning) is simply a list of all the other words to which it is connected. This is more consistent with a localist than with a distributed explanation. In fact, HAL actually does an excellent job of modeling the type of network originally proposed by Collins and Loftus (1975).

As was mentioned previously, many researchers have failed to acknowledge the important distinction Collins and Loftus (1975) made between semantic distance and semantic relatedness, with the former reflecting the shortest path between two nodes and the latter reflecting the weighted sum of all the connections between the two words. (However, see Lorch, 1982, for an important discussion of the speed vs. asymptote of associative activation.) Thus, the nodes STREET and LIGHT would not be strongly related, since they share only one asymmetrical connection (i.e., that from STREET to LIGHT). In contrast, as was discussed previously, the nodes STREET and ROAD would be strongly related because they share both a symmetrical connection and many indirect connections through other shared concepts, such as CAR, DRIVE, and GRAVEL. In this regard, HAL might actually be the best currently available implementation of Collins and Loftus's spreading activation model, because HAL is able to model both semantic distance and semantic relatedness, whereas association norms report only an overall strength measure. The HAL measures of co-occurrence frequency and Euclidean distance map almost perfectly onto
Collins and Loftus's concepts of semantic distance and semantic relatedness, respectively.

\section{HAL and Types of Semantic Relation}

Burgess and colleagues have demonstrated that the Euclidean distance between two words in HAL's highdimensional space reflects primarily semantic rather than associative relatedness. Likewise, Bueno and FrenckMestre (2002) recently constructed a French similarity matrix not unlike HAL and showed that synonym pairs were represented as closer together than associated pairs. Lund and Burgess (1996) also found that HAL accurately simulated human semantic similarity judgments. In addition, Lund, Burgess, and Audet (1996) found that HAL predicted priming for items that were semantic relatives or semantic + associative relatives, but not for items sharing only an associative relation. Finally, Lund et al. (Experiment 2) found no correlation between semantic distance as measured by HAL and association strength as measured by the Palermo and Jenkins (1964) association norms. ${ }^{14}$ However, aside from demonstrations that HAL stores semantic rather than associative relations, to my knowledge no formal attempts have been made using HAL to separately predict priming differences for other subtypes of semantic relations, such as instruments, scripts, antonyms, perceptual items, or similar function items.

\section{Lexical Co-occurrence and Mediated Priming}

An additional challenge to co-occurrence models such as HAL is to capture mediated relationships between words. As was discussed previously, Livesay and Burgess (1998) found that mediated items do not themselves co-occur and do not have more similar vectors of cooccurrence than unrelated controls (as reflected by distance in high-dimensional semantic space). However, unlike Livesay and Burgess, Chwilla and Kolk (2002) recently obtained evidence of mediated similarity using Landauer and colleagues' (Landauer \& Dumais, 1997; Landauer, Foltz, \& Laham, 1998) latent semantic analysis (LSA) model. Chwilla and Kolk found their mediated two-step and three-step stimuli to be more semantically related according to LSA than were unrelated controls. Thus, these two models seem divided in their a priori ability to account for mediated priming.

To test whether the conflicting results obtained between Chwilla and Kolk (2002) and Livesay and Burgess (1998) were due to the items used rather than to differences between LSA and HAL, I calculated the pairwise LSA values for Balota and Lorch's (1986) items used by Livesay and Burgess. The mean LSA similarity value of .20 for Balota and Lorch's mediated items was significantly greater than the .10 value given to these items when they were randomly re-paired to form unrelated controls $[t(47)=4.27, p<.001]$. Moreover, these values are strikingly similar to those obtained by Chwilla and Kolk for their own two-step mediated items (values of .20 and .12 for the mediated and control items in Ex- 
periment 1 , respectively, and values of .20 and .09 for the mediated and control items in Experiment 2, respectively). Therefore, the difference indeed reflects differences between LSA and HAL rather than differences between the items used in the two studies.

These results potentially bring into question the strongest evidence of associative priming-namely, that mediated priming is due to spreading activation. This alternative could be strengthened by studies showing that priming from these items is indeed more strongly correlated with direct contextual similarity (rather than mediated association strength). However, to my knowledge, no such studies have been conducted. Alternatively, even if such contextual similarity is related to priming, it is not exactly clear what this similarity reflects. For instance, although the words lion and stripes do not cooccur and their overall context vectors should differ substantially, it should be possible to capture their mutual co-occurrence with tiger in the model. In fact, it could even be this common word between the vectors for LION and STRIPES that produces the overall similarity values in LSA. If so, additional explorations might try lesioning this mediator word and all its connections from these networks and reconstructing the high dimensional matrices to see if the mediated items are still related. These ideas are still speculative, however, and further explorations of mediated priming within both HAL and LSA are needed to identify the role of mediated associations in both the LSA and HAL models. It is hoped that continued work in this area will supplement Lucas (2000) and the present review and provide an additional aid in determining the specific types of stimuli that do and do not produce automatic priming.

\section{REFERENCES}

Algarabel, S., Ruiz, J. C., \& SAnMart'́n, J. (1988). The University of Valencia's computerized word pool. Behavior Research Methods, Instruments, \& Computers, 20, 398-403.

ANDERSON, J. R. (1983). A spreading activation theory of memory. Journal of Verbal Learning \& Verbal Behavior, 22, 261-295.

ANDERSON, J. R., \& BOWER, G. H. (1973). Human associative memory. Washington, DC: Winston.

BALOTA, D. A. (1990). The role of meaning in word recognition. In D. A. Balota \& G. B. Flores d'Arcais (Eds.), Comprehension processes in reading (pp.9-32). Hillsdale, $\mathrm{NJ}$ : Erlbaum.

BALOTA, D. A., \& LoRCH, R. F. (1986). Depth of automatic spreading activation: Mediated priming effects in pronunciation but not in lexical decision. Journal of Experimental Psychology: Learning, Memory, \& Cognition, 12, 336-345.

BALOTA, D. A., \& PAUL, S. T. (1996). Summation of activation: Evidence from multiple primes that converge and diverge within semantic memory. Journal of Experimental Psychology: Learning, Memory, \& Cognition, 22, 827-845.

BALOTA, D. A., \& WATSON, J. M. (2000). [Mediated priming in the pronunciation task]. Unpublished raw data.

Balota, D. A., Watson, J. M., Duchek, J. M., \& Ferraro, F. R. (1999). Cross-modal semantic and homograph priming in healthy young, healthy old, and in Alzheimer's disease individuals. Journal of the International Neuropsychological Society, 5, 626-640.

BECKER,C. A. (1980). Semantic context effects in visual word recognition: An analysis of semantic strategies. Memory \& Cognition, 8, 493-512.

BennetT, D. J., \& MCEvoy,C. L. (1999). Mediated priming in younger and older adults. Experimental Aging Research, 25, 141-159.
Besner, D., Stolz, J. A., \& Boutilier, C. (1997). The Stroop effect and the myth of automaticity. Psychonomic Bulletin \& Review, 4, 221-225.

Brown, M. S., Roberts, M. A., \& Besner, D. (2001). Semantic processing in visual word recognition: Activation blocking and domain specificity. Psychonomic Bulletin \& Review, 8, 778-784.

Bueno, S., \& Frenck-Mestre, C. (2002). Rapid activation of the lexicon: A further investigation with behavioral and computational results. Brain \& Language, 81, 120-130.

BURGESS, C. (1998). From simple associations to the building blocks of language: Modeling meaning in memory with the HAL model. Behavior Research Methods, Instruments, \& Computers, 30, 188-198.

Burgess, C., \& Lund, K. (1995, November). Hyperspace analogue to language(HAL): A general model of semantic memory. Paper presented at the annual meeting of the Psychonomic Society, Los Angeles.

CARroll, M., \& KirSnER, K. (1982). Context and repetition effects in lexical decision and recognition memory. Journal of Verbal Learning \& Verbal Behavior, 21, 55-69.

ChiApPe, P. R., SMith, M. C., \& Besner, D. (1996). Semantic priming in visual word recognition: Activation blocking and domains of processing. Psychonomic Bulletin \& Review, 3, 249-253.

ChIARELlo, C. (1998). On codes of meaning and the meaning of codes: Semantic access and retrieval within and between hemispheres. In M. Beeman \& C. Chiarello (Eds.), Right hemisphere language communication: Perspectives from cognitive neuroscience (pp. 141-160). Mahwah, NJ: Erlbaum.

Chiarello, C., Burgess, C., Richards, L., \& Pollock, A. (1990). Semantic and associative priming in the cerebral hemispheres: Some words do, some words don't . . . sometimes, some places. Brain \& Language, 38, 75-104.

Chwilla, D. J., \& Kolk, H. H. J. (2002). Three-step priming in lexical decision. Memory \& Cognition, 30, 217-225.

Chwilla, D. J., KolK, H. H. J., \& Mulder, G. (2000). Mediated priming in the lexical decision task: Evidence from event-related potentials and reaction time. Journal of Memory \& Language, 42, 314-341.

Collins, A. M., \& LofTus, E. F. (1975). A spreading activation theory of semantic processing. Psychological Review, 82, 407-428.

Dagenbach, D., Horst, S., \& CARR, T. H. (1990). Adding new information to semantic memory: How much learning is enough to produce automatic priming? Journal of Experimental Psychology: Learning, Memory, \& Cognition, 16, 581-591.

DAVElaAR, E., \& ColtheART, M. (1975). Effects of interpolated items on the association effect in lexical decision tasks. Bulletin of the Psychonomic Society, 6, 269-272.

DEESE, J. (1965). The structure of associations in language and thought. Baltimore, MD: Johns Hopkins University Press.

DE Groot, A. M. B. (1983). The range of automatic spreading activation in word priming. Journal of Verbal Learning \& Verbal Behavior, 22, 417-436.

DE Groot, A. M. B. (1984). Primed lexical decision: Combined effects of the proportion of related prime-target pairs and the stimulus-onset asynchrony of prime and target. Quarterly Journal of Experimental Psychology, 36A, 253-280.

DE Groot, A. M. B. (1990). The locus of the associative priming effect in the mental lexicon. In D. A. Balota \& G. B. Flores d'Arcais (Eds.), Comprehension processes in reading (pp. 101-123). Hillsdale, NJ: Erlbaum.

De Mornay Davies, P. (1998). Automatic semantic priming: The contribution of lexical- and semantic-level processes. European Journal of Cognitive Psychology, 10, 389-412.

DEN HEYER, K. (1985). On the nature of the proportion effect in semantic priming. Acta Psychologica, 60, 25-38.

DEN Heyer, K., Briand, K., \& DAnNenbring, G. L. (1983). Strategic factors in a lexical-decision task: Evidence for automatic and attentiondriven processes. Memory \& Cognition, 11, 374-381.

Durante, R., \& Hirshman, E. (1994). Retrospective priming and masked semantic priming: The interfering effects of prime activation. Journal of Memory \& Language, 33, 112-127.

DurgunoĞlu, A. Y., \& Neely, J. H. (1987). On obtaining episodic priming in a lexical decision task following paired-associate learning. Journal of Experimental Psychology: Learning, Memory, \& Cognition, 13, 206-222. 
FARAH, M. J., \& MCCLELland, J. L. (1991). A computational model of semantic memory impairment: Modality specificity and emergent category specificity. Journal of Experimental Psychology: General, 120, 339-357.

FISCHLER, I. (1977). Semantic facilitation without association in a lexical decision task. Memory \& Cognition, 5, 335-339.

Flores d'Arcais, G. B., Schreuder, R., \& Glazenborg, G. (1985). Semantic activation during recognition of referential words. Psychological Research, 47, 39-49.

FODOR, J. A. (1983). Modularity of mind. Cambridge, MA: MIT Press. FolTZ, P. W. (1996). Latent semantic analysis for text-based research. Behavior Research Methods, Instruments, \& Computers, 28, 197-202.

FORSTER, K. I. (1979). Levels of processing and the structure of the language processor. In W. E. Cooper \& E. C. T. Walker (Eds.), Sentence processing: Psycholinguistic studies presented to Merrill Garrett (pp. 27-85). Hillsdale, NJ: Erlbaum.

FrenCK-Mestre, C., \& Bueno, S. (1999). Semantic features and semantic categories: Differences in rapid activation of the lexicon. Brain \& Language, 68, 199-204.

Friedrich, F. J., HENIK, A., \& TzELgOv, J. (1991). Automatic processes in lexical access and spreading activation. Journal of Experimental Psychology: Human Perception \& Performance, 17, 792-806.

HAYES, S. C., \& BisseTt, R. T. (1998). Derived stimulus relations produce mediated and episodic priming. Psychological Record, 48, 617 630.

Hines, D., Czerwinski, M., SAWyer, P. K., \& DWyer, M. (1986). Automatic semantic priming: Effect of category exemplar level and word association level. Journal of Experimental Psychology: Human Perception \& Performance, 12, 370-379.

HodGson, J. M. (1991). Informational constraints on pre-lexical priming. Language \& Cognitive Processes, 6, 169-205.

Hunt, M. (1997). How science takes stock. New York: Sage.

Hutchison, K. A. (2002). The effect of asymmetrical association on positive and negative semantic priming. Memory \& Cognition, 30, 1263-1276.

Hutchison, K. A., Neely, J. H., \& Johnson, J. D. (2001). With great expectations, can two "wrongs" prime a "right"? Journal of Experimental Psychology: Learning, Memory, \& Cognition, 27, 1451-1463.

JONIDES, J., \& MACK, R. (1984). On the cost and benefit of cost and benefit. Psychological Bulletin, 96, 29-44.

KAHAN, T. A. (2000). Negative priming from masked words: Retrospective prime clarification or center-surround inhibition? Journal of Experimental Psychology: Learning, Memory, \& Cognition, 26, 1392-1410.

Kahan, T. A., Neely, J. H., \& Forsythe, W. J. (1999). Dissociated backward priming effects in lexical decision and pronunciation tasks. Psychonomic Bulletin \& Review, 6, 105-110.

KATZ, J. J., \& FodOR, J. A. (1963). The structure of semantic theory. Language, 39, 170-210.

KAWAMOTO, A. H. (1988). Distributed representations of ambiguous words and their resolution in a connectionist network. In S. I. Small, G. W. Cottrell, \& M. K. Tanenhaus (Eds.), Lexical ambiguity resolution. San Mateo, CA: Morgan Kaufmann.

KAWAMOTO, A. H. (1993). Nonlinear dynamics in the resolution of lexical ambiguity: A parallel distributed processing account. Journal of Memory \& Language, 32, 474-516.

Keefe, D. E., \& Neely, J. H. (1990). Semantic priming in the pronunciation task: The role of prospective prime-generated expectancies. Memory \& Cognition, 18, 289-298.

Kent, G. H., \& RosanofF, A. J. (1910). A study of association in insanity. American Journal of Insanity, 62, 37-96, 317-390.

KigER, J. I., \& GLASS, A. L. (1983). The facilitation of lexical decisions by a prime occurring after the target. Memory \& Cognition, 11, 356365.

Koriat, A. (1981). Semantic facilitation in lexical decision as a function of prime-target association. Memory \& Cognition, 9, 587-598.

LAMBERT, W. E., \& MoORE, N. (1966). Word association responses: Comparisons of American and French monolinguals with Canadian monolinguals and bilinguals. Journal of Personality \& Social Psychology, 3, 313-320.

Landauer, T. K., \& Dumais, S. T. (1997). A solution to Plato's prob- lem: The latent semantic analysis theory of acquisition, induction, and representation of knowledge. Psychological Review, 104, 211240.

LANDAuer, T. K., Foltz, P. W., \& LAHAM, D. (1998). An introduction to latent semantic analysis. Discourse Processes, 25, 259-284.

LIVESAY, K., \& BURGESS, C. (1998). Mediated priming in high-dimensional semantic space: No effect of direct semantic relationships or cooccurrence. Brain \& Cognition, 37, 102-105.

LORCH, R. F. (1982). Priming and search processes in semantic memory: A test of three models of spreading activation. Journal of Verbal Learning \& Verbal Behavior, 21, 468-492.

LUCAS, M. (2000). Semantic priming without association: A meta-analytic review. Psychonomic Bulletin \& Review, 7, 618-630.

LuCAS, M. (2001). Essential and perceptual attributes of words in reflective and on-line processing. Journal of Psycholinguistic Research, 30, 605-625.

Lund, K., \& Burgess, C. (1996). Producing high-dimensional semantic spaces from lexical co-occurrence. Behavior Research Methods, Instruments, \& Computers, 28, 203-208.

Lund, K., Burgess, C., \& Audet, C. (1996). Dissociating semantic and associative word relationships using high-dimensional semantic space. In Proceedings of the Eighteenth Annual Conference of the Cognitive Science Society (pp. 603-608). Mahwah, NJ: Erlbaum.

LUPKER, S. J. (1984). Semantic priming without association: A second look. Journal of Verbal Learning \& Verbal Behavior, 23, 709-733.

LYONS, J. (1968). Introduction to theoretical linguistics. London: Cambridge University Press.

Mar'-Beffa, P., Fuentes, L. J., Catena, A., \& Houghton, G. (2000). Semantic priming in the prime task effect: Evidence of automatic semantic processing of distractors. Memory \& Cognition, 28, 635-647.

Masson, M. E. J. (1995). A distributed memory model of semantic priming. Journal of Experimental Psychology: Learning, Memory, \& Cognition, 21, 3-23.

MCClelland, J. L., \& Rume LhaRT, D. E. (1981). An interactive activation model of context effects in letter perception: I. An account of basic findings. Psychological Review, 88, 375-407.

MCClelland, J. L., \& RuMElhart, D. E. (1985). Distributed memory and the representation of general and specific information. Journal of Experimental Psychology: General, 114, 159-188.

McKoon, G., \& RatCliff, R. (1979). Priming in episodic and semantic memory. Journal of Verbal Learning \& Verbal Behavior, 18, 463480.

MCKoon, G., \& RATCLIFF, R. (1992). Spreading activation versus compound cue accounts of priming: Mediated priming revisited. Journal of Experimental Psychology: Learning, Memory, \& Cognition, 18, 1155-1172.

McKoon, G., \& RATCLIFF, R. (1995). Conceptual combinations and relational contexts in free association and in priming in lexical decision and naming. Psychonomic Bulletin \& Review, 2, 527-533.

MCNAmara, T. P. (1992). Theories of priming: I. Associative distance and lag. Journal of Experimental Psychology: Learning, Memory, \& Cognition, 18, 1173-1190.

MCNAmara, T. P., \& Altarriba, J. (1988). Depth of spreading activation revisited: Semantic mediated priming occurs in lexical decisions. Journal of Memory \& Language, 27, 545-559.

MCRAe, K., \& BoIsvert, S. (1998). Automatic semantic similarity priming. Journal of Experimental Psychology: Learning, Memory, \& Cognition, 24, 558-572.

McRAe, K., De SA, V. R., \& Seidenberg, M. S. (1997). On the nature and scope of featural representations of word meaning. Journal of Experimental Psychology: General, 126, 99-130.

Meyer, D. E., \& SChVAneveldt, R. W. (1971). Facilitation in recognizing pairs of words: Evidence of a dependence between retrieval operations. Journal of Experimental Psychology, 90, 227-234.

Meyer, D. E., SchVANE Veldt, R. W., \& Ruddy, M. G. (1975). Loci of contextual effects in visual word recognition. In P. M. A. Rabbitt (Ed.), Attention and performance V (pp. 98-118). New York: Academic Press.

Morton, J. A. (1969). Interaction of information in word recognition. Psychological Review, 76, 165-178.

Moss, H. E., HARE, M. L., DAY, P., \& TYler, L. K. (1994). A distributed 
memory model of the associative boost in semantic priming. Connection Science, 6, 413-427.

Moss, H. E., MCCORMICK, S. F., \& TYLER, L. K. (1997). The time course of activation of semantic information during spoken word recognition. Language \& Cognitive Processes, 12, 695-731.

Moss, H. E., Ostrin, R. K., Tyler, L. K., \& Marslen-Wilson, W. D. (1995). Accessing different types of lexical semantic information: Evidence from priming. Journal of Experimental Psychology: Learning, Memory, \& Cognition, 21, 863-883.

Nation, K., \& SnOwling, M. J. (1999). Developmental differences in sensitivity to semantic relations among good and poor comprehenders: Evidence from semantic priming. Cognition, 70, B1-B13.

NEELY, J. H. (1977). Semantic priming and retrieval from lexical memory: Roles of inhibitionless spreading activation and limited-capacity attention. Journal of Experimental Psychology: General, 106, 226-254.

NEELY, J. H. (1991). Semantic priming effects in visual word recognition: A selective review of current findings and theories. In D. Besner \& G. W. Humphreys (Eds.), Basic processes in reading: Visual word recognition (pp. 264-336). Hillsdale, NJ: Erlbaum.

Neely, J. H., \& DurgunoĞlu, A. Y. (1985). Dissociative episodic and semantic priming effects in episodic recognition and lexical decision tasks. Journal of Memory \& Language, 24, 466-489.

NEELY, J. H., \& KAHAN, T. A. (2001). Is semantic activation automatic? A critical re-evaluation. In H. L. Roediger III, J. S. Nairne, I. Neath, \& A. M. Surprenant (Eds.), The nature of remembering: Essays in honor of Robert G. Crowder (pp. 69-93). Washington, DC: American Psychological Association.

NeEly, J. H., \& KeEFe, D. E. (1989). Semantic context effects in visual word processing: A hybrid prospective/retrospective processing theory. In G. H. Bower (Ed.), The psychology of learning and motivation: Advances in research and theory (Vol. 24, pp. 207-248). New York: Academic Press.

Neely, J. H., \& SloAt, J. (1992, November). Dissociative mediated, backward and forward priming for lexical decisions. Paper presented at the 33rd Annual Meeting of the Psychonomic Society, St. Louis.

Nelson, D. L., McEvoy, C. L., \& Schreiber, T. (1999). University of South Florida word association, rhyme and word fragment norms. Available at http://cyber.acomp.usf.edu/FreeAssociation/.

Ostrin, R. K., \& TYLER, L. K. (1993). Automatic access to lexical semantics in aphasia: Evidence from semantic and associative priming. Brain \& Language, 45, 147-159.

PAle RMo, D. S., \& Jenkins, J. J. (1964). Word association norms: Grade school through college. Minneapolis: University of Minnesota Press.

Pecher, D., \& RaAijmakers, J. G. W. (1999). Automatic priming effects for new associations in lexical decision and perceptual identification. Quarterly Journal of Experimental Psychology: Human Experimental Psychology, 52A, 593-614.

Pecher, D., Zeelenberg, R., \& RaAijmakers, J. G. W. (1998). Does pizza prime coin? Perceptual priming in lexical decision and pronunciation. Journal of Memory \& Language, 38, 401-418.

Perea, M., \& Gotor, A. (1996). Associative and semantic priming effects occur at very short stimulus-onset asynchronies in lexical decision and naming. Cognition, 62, 223-240.

PereA, M., Gotor, A., \& NÁCHER, M. J. (1997). Efectos de facilitación asociativa vs. semántica con una breve asincronía estimular señaltest [Associative and semantic priming effects at a very brief stimulus onset asynchrony]. Psicothema, 9, 509-517.

Perea, M., \& RosA, E. (2002). The effects of associative and semantic priming in the lexical decision task. Psychological Research, 66, 180194.

Peterson, R. R., \& Simpson, G. B. (1989). The effect of backward priming on word recognition in single-word and sentence contexts. Journal of Experimental Psychology: Learning, Memory, \& Cognition, 15, 1020-1032.

Plaut, D. C. (1995). Double dissociation without modularity: Evidence from connectionist neuropsychology. Journal of Clinical \& Experimental Neuropsychology, 17, 291-321.

Plaut, D. C., \& BOOTH, J. R. (2000). Individual and developmental differences in semantic priming: Empirical and computational support for a single-mechanism account of lexical processing. Psychological Review, 107, 786-823.
Plaut, D. C., McClelland, J. L., Seidenberg, M. S., \& Patterson, K. (1996). Understanding normal and impaired word reading: Computational principles in quasi-regular domains. Psychological Review, 105, 56-115.

Posner, M. I., \& SNYDER, C. R. (1975). Attention and cognitive control. In R. L. Solso (Ed.), Information processing and cognition (pp. 55-85). Hillsdale, NJ: Erlbaum.

RosCH, E. (1973). On the internal structure of perceptual and semantic categories. In T. E. Moore (Ed.), Cognitive development and acquisition of language (pp. 111-144). New York: Academic Press.

Rosch, E. (1975). Cognitive representations of semantic categories. Journal of Experimental Psychology: General, 104, 192-233.

Rosenthal, R., \& DiMatteo, M. R. (2001). Meta-analysis: Recent developments in quantitative methods for literature reviews. Annual Review of Psychology, 52, 59-82.

RoSENZWEIG, M. R. (1970). International Kent-Rosanoff word association norms, emphasizing those of French male and female students and French workers. In L. Postman \& G. Keppel (Eds.), Norms of word association (pp. 95-176). New York: Academic Press.

Rumelhart, D. E., Smolensky, P., McClelland, J. L., \& Hinton, G. E. (1986). Schemata and sequential thought processes in PDP models. In J. L. McClelland \& D. E. Rumelhart (Eds.), Parallel distributed processes: Explorations in the microstructure of cognition (pp. 7-57). Cambridge, MA: MIT Press.

Sayette, M. A., Hufford, M. R., \& Thorson, G. M. (1996). Development of a brief measure of semantic priming. Journal of Clinical \& Experimental Neuropsychology, 18, 678-684.

SCHANK, R. C., \& AbELSON, R. P. (1977). Scripts, plans, goals, and understanding: An inquiry into human knowledge structures. Hillsdale, NJ: Erlbaum.

Schreuder, R., Flores d'Arcais, G. B., \& Glazenborg, G. (1984). Effects of perceptual and conceptual similarity in semantic priming. Psychological Research, 45, 339-354.

SeidenberG, M. S., \& MCClelland, J. L. (1989). A distributed, developmental model of word recognition and naming. Psychological Review, 96, 523-568.

SeidenberG, M. S., WATERs, G. S., SANDERs, M., \& LANGer, P. (1984). Pre- and postlexical loci of contextual effects on word recognition. Memory \& Cognition, 12, 315-328.

ShARKEY, A. J., \& SHARKEY, N. E. (1992). Weak contextual constraints in text and word priming. Journal of Memory \& Language, 31, 543572 .

Shelton, J. R., \& Caramazza, A. (1999). Deficits in lexical and semantic processing: Implications for models of normal language. Psychonomic Bulletin \& Review, 6, 5-27.

Shelton, J. R., \& MARTIN, R. C. (1992). How semantic is automatic semantic priming? Journal of Experimental Psychology: Learning, Memory, \& Cognition, 18, 1191-1210.

Smith, E. E. (1978). Theories of semantic memory. In W. K. Estes (Ed.), Handbook of learning and cognitive processes (Vol. 6, pp. 156). Hillsdale, NJ: Erlbaum.

SPENCE, D. P., \& OWENS, K. C. (1990). Lexical co-occurrence and association strength. Journal of Psycholinguistic Research, 19, 317 330 .

Stolz, J. A., \& BeSNER, D. (1996). Role of set in visual word recognition: Activation and activation blocking as nonautomatic processes. Journal of Experimental Psychology: Human Perception \& Performance, 22, 1166-1177.

STOLZ, J. A., \& BESNER, D. (1998). Levels of representation in visual word recognition: A dissociation between morphological and semantic processing. Journal of Experimental Psychology: Human Perception \& Performance, 24, 1642-1655.

Tanenhaus, M. K., \& Lucas, M. M. (1987). Context effects in lexical processing. Cognition, 25, 213-234.

Thompson-Schill, S. L., Kurtz, K. J., \& Gabrieli, J. D. E. (1998). Effects of semantic and associative relatedness on automatic priming. Journal of Memory \& Language, 38, 440-458.

Tversky, A. (1977). Features of similarity. Psychological Review, 84, 327-352.

TVERSKy, A., \& GATI, I. (1982). Similarity, separability, and the triangle inequality. Psychological Review, 89, 123-154.

Tweedy, J. R., LApinski, R. H., \& SchVane Veldt, R. W. (1977). 
Semantic-context effects on word recognition: Influence of varying the proportion of items presented in an appropriate context. Memory \& Cognition, 5, 84-89.

Tyler, L. K., Moss, H. E., Galpin, A., \& Voice, J. K. (2002). Activating meaning in time: The role of imageability and form-class. Language \& Cognitive Processes, 17, 471-502.

WARRINGTON,E. K., \& MCCARTHY, R. A. (1987). Categories of knowledge: Further fractionations and an attempted integration. Brain, 110, 1273-1296.

WARrington, E. K., \& Shallice, T. (1984). Category specific semantic impairments. Brain, 107, 829-854.

WENTURA, D. (2000). Dissociative affective and associative priming effects in the lexical decision task: Yes versus no responses to word targets reveal evaluative judgment tendencies. Journal of Experimental Psychology: Learning, Memory, \& Cognition, 26, 456-469.

WhittleseA, B. W., \& JACOBY, L. L. (1990). Interaction of prime repetition and visual degradation: Is priming a retrieval phenomenon? Journal of Memory \& Language, 29, 546-565.

WiLliAMS, J. N. (1996). Is automatic priming semantic? European Journal of Cognitive Psychology, 22, 139-151.

ZWITSERLOOD, P., \& SCHRIEFERS, H. (1995). Effects of sensory information and processing time in spoken-word recognition. Language \& Cognitive Processes, 10, 121-136.

\section{NOTES}

1. As a convention, I use italics to designate lexical items and word pairs (e.g., the word cherry and the word pair cherry-fruit) and small capital letters to designate semantic concepts (e.g., the concept of CHERRY).

2. This is not meant to imply that participants never intentionally use semantic information in their decisions. Indeed, with a high proportion of related trials, semantically based strategies have been found to increase semantic priming (see Neely, 1991, for a review). Two such possible strategies (e.g., conscious expectancies and strategic semantic matching) are discussed in this article.

3. Some authors have suggested that semantic priming is not truly automatic in that focusing attention on an individualletter reduces or eliminates semantic priming (Besner, Stolz, \& Boutilier, 1997; Brown, Roberts, \& Besner, 2001; Chiappe, Smith, \& Besner, 1996; Friedrich, Henik, \& Tzelgov, 1991; Stolz \& Besner, 1996, 1998). However, others have argued that such experiments do not provide compelling evidence against the automaticity of semantic activation (Hutchison, Neely, \& Johnson, 2001; Marí-Beffa, Fuentes, Catena, \& Houghton, 2000; Neely \& Kahan, 2001).

4. Jim Neely clarified this misinterpretation during a personal communication (June 13, 2002).

5. However, Chwilla and Kolk (2002) have also found such three-step priming using a more traditional two-word procedure, which suggests that the continuous procedure is not critical for the effect to be obtained.

6. I am aware of two research laboratories with unpublished studies in which mediated priming was examined. In one lab, Balota and Watson (2000) found a significant 8-msec mediated priming effect in pronunciation. In another lab, Neely and Sloat (1992) tested mediated priming in both standard and go/no-go versions of the LDT. Across eight experiments, their effects ranged from 5 to $22 \mathrm{msec}(M=$ $13 \mathrm{msec}$ ). The mediated priming effect was significant in all but one study. Thus, the significant effects described in the text are unlikely to be due to a publication-oriented bias toward positive results.
7. The term backward priming has also been used by Kiger and Glass (1983) to explain facilitation in lexical decision for a target (e.g., apple) when its forward-associated prime (e.g., fruit) briefly lags behind the target in presentation. It was suggested that the priming obtained in this task was due to the temporal overlap in processing between the prime and the target. This procedure and interpretation are different from the current meaning of backward priming, in which participants respond to the second item presented and the terms forward and backward refer to the direction in which the prime-target pairs are associated.

8. Perhaps due to the dominance of spreading activation theories in the 1970 s and early 1980 s, none of the early researchers mentioned this feature-based account as a plausible explanation of their findings. Instead, researchers such as Koriat (1981) attempted to "fix" the spreading activation account by suggesting that the target reactivates the prime, allowing forward priming from the prime to activate the target. Clearly, this interpretation is more cumbersome (and circular) than a feature-based explanation. It also demonstrates the difficulty of disproving a spreading activation explanation for any priming effect.

9. One could design an experiment to eliminate this problem by including prime-target pairs that are associatively or categorically related yet entail different responses. For instance, suppose one asked the question "Is it flat?" and included semantically related pairs such as pastrymuffin that should elicit different responses. If the effect takes place prelexically, then one should still expect priming from these items. If, instead, the prime merely influences the decision process, then one would expect priming only when both the prime and the target are associated with the same response (e.g., pancake-waffle). Although I know of no experiments in which this procedure has been used, my prediction is that relatedness influences primarily the decision process in this task, and one would therefore obtain either no effect or an inhibitory effect of related items in the incongruent situation.

10. For each study, there were some items (usually of low frequency) that were not listed in the Nelson et al. (1999) norms. However, the association strength was available for a majority of items in each experiment, and the overall association strength given represents the average strength from these available items.

11. One may question the strength of evidence for Lupker's (1984) conclusions. Although his pure semantic priming effects in naming were small, they were statistically significant and replicated across experiments. Indeed, other researchers have found that priming effects in naming are usually numerically only about half the size of that found in lexical decision (see Neely, 1991, for a review).

12. Because their "conceptually similar" items all performed the same function, I have included them under the heading "Same function" in Table 6 .

13. Moss et al. (1995) also included both artificial and natural category members in their experiment. However, because their priming effects from these items were discussed previously, they are not mentioned here.

14. As with the HAL model, Landauer and colleagues' (Landauer \& Dumais, 1997; Landauer, Foltz, \& Laham, 1998) LSA model has also been shown to validly predict human comprehension, categorization, and priming performance.

(Manuscript received August 15, 2002; revision accepted for publication March 6, 2003.) 